\title{
Incomplete lineage sorting and ancient admixture, and speciation without morphological change in ghost-worm cryptic species
}

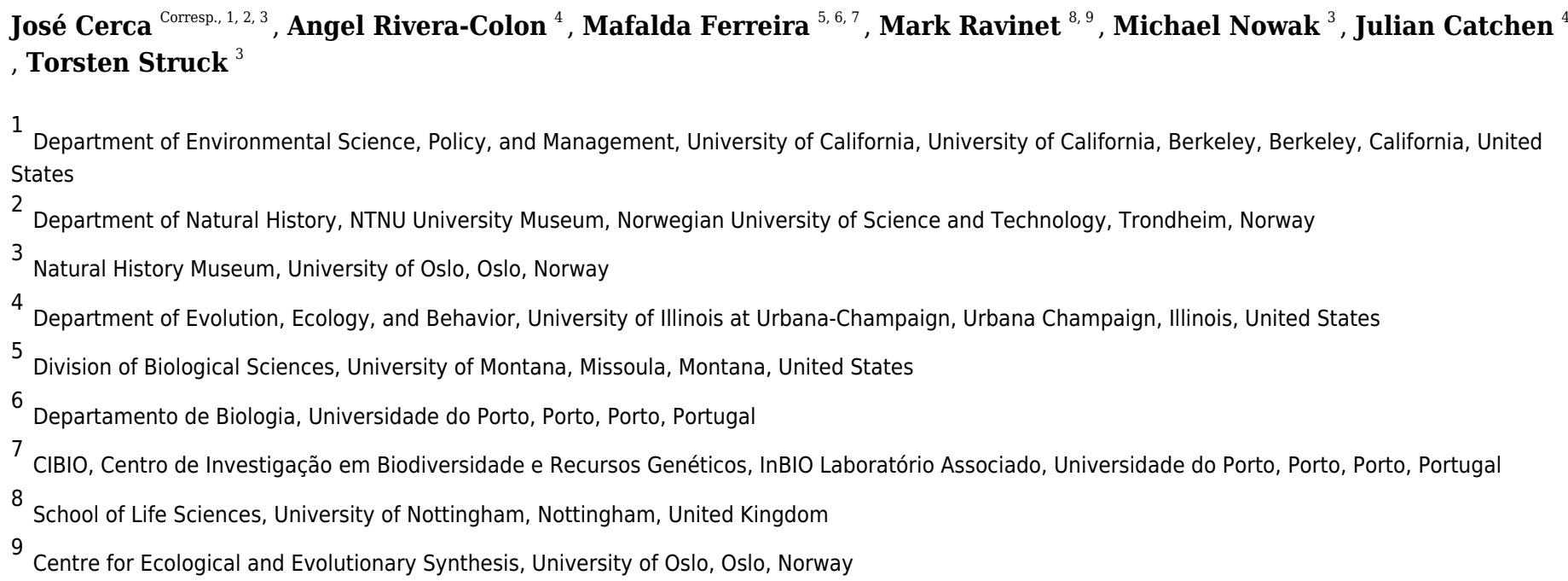

Morphologically similar species, that is cryptic species, may be similar or quasi-similar owing to the deceleration of morphological evolution and stasis. While the factors underlying the deceleration of morphological evolution or stasis in cryptic species remain unknown, decades of research in the field of paleontology on punctuated equilibrium have originated clear hypotheses. Species are expected to remain morphologically identical in scenarios of shared genetic variation, such as hybridization and incomplete lineage sorting, or in scenarios where bottlenecks reduce genetic variation and constrain the evolution of morphology. Here, focusing on three morphologically similar Stygocapitella species, we employ a whole-genome amplification method (WGA) coupled with doubledigestion restriction-site associated DNA sequencing (ddRAD) to reconstruct the evolutionary history of the species complex. We explore population structure, use population-level statistics to determine the degree of connectivity between populations and species, and determine the most likely demographic scenarios which generally reject for recent hybridization. We find that the combination of WGA and ddRAD allowed us to obtain genomic-level data from microscopic eukaryotes ( $\sim$ millimetre) opening up opportunities for those working with population genomics and phylogenomics in such taxa. The three species share genetic variance, likely from incomplete lineage sorting and ancient admixture. We speculate that the degree of shared variation might underlie 
morphological similarity in the Atlantic species complex. 
1 Incomplete lineage sorting and ancient admixture, and speciation without morphological change in ghost-worm cryptic species

3 José Cerca ${ }^{1,2,3}$, Angel Rivera-Colón ${ }^{4}$, Mafalda S. Ferreira ${ }^{5,6,7}$, Mark Ravinet ${ }^{8,9}$, Michael D.

4 Nowak $^{1}$, Julian Catchen ${ }^{4}$, Torsten H. Struck ${ }^{1}$

$5 \quad{ }^{1}$ Natural History Museum, University of Oslo, Oslo, Norway

$6{ }^{2}$ Department of Environmental Science, Policy, and Management, University of California,

7 Berkeley, CA, USA

$8{ }^{3}$ Department of Natural History, NTNU University Museum, Norwegian University of Science

9 and Technology, Trondheim, Norway

$10{ }^{4}$ Department of Evolution, Ecology, and Behavior, University of Illinois at Urbana-Champaign

$11{ }^{5}$ CIBIO, Centro de Investigação em Biodiversidade e Recursos Genéticos, InBIO Laboratório

12 Associado, Universidade do Porto, Vairão, Portugal

$13{ }^{6}$ Departamento de Biologia, Faculdade de Ciências da Universidade do Porto, Porto, Portugal

$14{ }^{7}$ Division of Biological Sciences, University of Montana, Missoula, Montana, USA

$15{ }^{8}$ Centre for Ecological and Evolutionary Synthesis, University of Oslo

$16{ }^{9}$ School of Life Sciences, University of Nottingham, UK

Corresponding Author:

19 José Cerca ${ }^{1}$

ORCID 0000-0001-7788-4367

Sars' Gate 1, Oslo, Norway

Email address: jose.cerca@ntnu.no

\section{Abstract}

Morphologically similar species, that is cryptic species, may be similar or quasi-similar owing to the deceleration of morphological evolution and stasis. While the factors underlying the deceleration of morphological evolution or stasis in cryptic species remain unknown, decades of research in the field of paleontology on punctuated equilibrium have originated clear hypotheses. Species are expected to remain morphologically identical in scenarios of shared genetic variation, such as hybridization and incomplete lineage sorting, or in scenarios where bottlenecks reduce genetic variation and constrain the evolution of morphology. Here, focusing on three morphologically similar Stygocapitella species, we employ a whole-genome amplification method (WGA) coupled with double-digestion restriction-site associated DNA sequencing (ddRAD) to reconstruct the evolutionary history of the species complex. We explore population structure, use population-level statistics to determine the degree of connectivity between populations and species, and determine the most likely demographic scenarios which generally reject for recent hybridization. We find that the combination of WGA and ddRAD allowed us to 
obtain genomic-level data from microscopic eukaryotes ( $\sim 1$ millimetre) opening up opportunities for those working with population genomics and phylogenomics in such taxa. The three species share genetic variance, likely from incomplete lineage sorting and ancient admixture. We speculate that the degree of shared variation might underlie morphological similarity in the Atlantic species complex.

\section{Introduction}

The characterization and delimitation of species and populations using DNA sequencing and barcoding has led to the discovery of 'hidden species diversity' in previously established species (Knowlton 1993; Bickford et al. 2007; Pfenninger and Schwenk 2007; Struck et al. 2018). The initial interest in this hidden diversity, that is cryptic species, fuelled a debate on whether these lineages resulted from biases of a morphologically oriented classification of biodiversity or whether they resulted from underlying biological phenomena. On one side, proponents of the "artefact model" suggest that populations and species naturally accumulate morphological differences, and it is only the limitations associated with scientific methods that impede the discovery of those differences (Korshunova et al. 2017). On the one other side, the "evolutionary framework" suggests that the deceleration of morphological evolution is a plausible expectation, given the observation of stasis, niche conservatism and constraints in nature. While some of this diversity is potentially attributed to taxonomic artefacts (Korshunova et al. 2017), morphologically similar species - 'true' cryptic species - have been discovered in various branches of the tree of life, thus representing an important part of biodiversity (Pfenninger and Schwenk 2007; PérezPonce de León and Poulin 2016; Cerca et al. 2018; Fišer et al. 2018).

Following centuries of morphologically oriented taxonomy, the existence of "true" cryptic species entails a challenge to the delimitation, discovery and classification of species (Bickford et al. 2007; Fišer et al. 2018; Struck et al. 2018). In the case of morphologically similar species, species delimitation relying on morphology alone will fail to capture the existing species diversity (Pante et al. 2015; Fišer et al. 2018; Chenuil et al. 2019; Struck and Cerca 2019), resulting in the lumping of different species into a single species complex. While much has been written on the consequences of cryptic species in terms of biological systematics, we have only recently begun to understand the impact of cryptic species in other fields of biology. When species are poorly delimited, determination of biogeographic breaks (Weber et al. 2019; Cerca et al. 2020a), inferences on the evolutionary history (Wada et al. 2013; Swift et al. 2016; Struck et al. 2018; 
Dufresnes et al. 2019), and the determination of ecological richness of an ecosystem (Chenuil et al. 2019) may be severely compromised. These problems extend outside fundamental fields of biology when species complexes are medically-relevant, such as the Anopheles cryptic species complex where not every morphologically-similar species is capable of transmitting malaria (Erlank et al. 2018) or in parasite species (De León and Nadler 2010; Nadler and De Len 2011), but also in cases of conservation management (Bickford et al. 2007; Bernardo 2011).

While the discovery of cryptic species complexes has increased in the last few years, the resulting debate has focused on whether these are taxonomic artefacts or biologically relevant species. Consequently, the causes underlying morphological similarity remain mostly unexplored. Despite this hindrance, an important source of information may come from palaeontology where stasis has been studied for decades (Eldredge and Gould 1972; Gould 2002), and from the subsequent integration of this evidence with neontological data. A particularly insightful contribution is that of Futuyma (2010), which suggests that stasis may result from certain ecological, genetic and developmental scenarios. Genetic scenarios include shared genetic variation, potentially resulting from hybridization or ILS, homogenizing morphological divergence; genetic constraints resulting from epistatic reactions or pleiotropy, or constrains from the lack of genetic variation due to repeated bottlenecks or founder effects; stabilizing selection on morphology (Futuyma 2010). Some of these scenarios including stabilizing selection (Lee and Frost 2002; Novo et al. 2010, 2012; Lavoué et al. 2011; Smith et al. 2011; Santamaria et al. 2016; Zuccarello et al. 2018), bottlenecks and founder effects (Dornburg et al. 2016; Valtueña et al. 2016) have been proposed to explain similarity on cryptic species. However, this remains untested since evidence for morphological similarity comes mostly from the interpretation of indirect methods, such as phylogenetic trees.

The Stygocapitella genus includes 11 described species with only four morphotypes and no significant quantitative morphological differences between some species (Cerca et al. 2020a, b). Morphologically identical species occur in sympatry and overlap in their distribution along the Northern European, Atlantic American, and Pacific American coastlines. In a previous study, we confirmed that three North Atlantic species - Stygocapitella westheidei, S. subterranea, and $S$. josemariobrancoi - are morphologically identical (Cerca et al. 2020a), nonetheless, we were not able to determine the causes underlying morphological similarity with certainty. Preliminary 
100 results from selected DNA markers indicated that morphological similarity potentially stems from 101 niche conservatism and niche tracking, coupled with the fluctuating dynamics of their habitats 102 and/or genetic constraints (Cerca et al. 2020b). Here, using genomic data, we extend these efforts 103 by focusing on the causes linked to genetic variation underlying morphological similarity (see 104 above). Following Futuyma (2010), we hypothesize that 1) bottlenecks and founder effects reduce 105 genetic variation, thus resulting in morphological similarity; 2) morphological similarity results from recent admixture; 3) shared genetic variation due to incomplete lineage sorting and ancient admixture underlies morphological similarity.

Methods and materials

\section{Study system}

Stygocapitella is part of the meiofauna, being generally found above the high-water line of sheltered gravel or sandy beaches. To collect individuals, we selected sampling areas based on old records or by assessing beaches using google maps (Supplementary Table 1; Fig. 1). At each site, we drew a transect from the high-water line to the foot of the dune, digging a 1-meter deep hole every meter starting at the high-water line. In each hole, we collected sediment samples every 15 $\mathrm{cm}$ of depth with a volume of about $500 \mathrm{~cm}^{3}$. Sediment samples were brought to the laboratory and interstitial invertebrates were extracted using the $\mathrm{MgCl}_{2}$ method, and isolated using a dissecting microscope (Westheide and Purschke 1988). After identifying Stygocapitella, we collected and preserved these in a $\sim 70 \%$ ethanol solution for DNA extraction.

\section{DNA extraction and molecular species barcoding}

Since Stygocapitella westheidei, S. subterranea and $S$. josemariobrancoi are morphologically indistinguishable (Cerca et al. 2020a), we barcoded individual individuals using 16S, 18S, ITS1 and COI as described in Cerca et al. (2020b, a) (Supplementary Table 2 includes NCBI reference-ID). In brief, we extracted DNA from single individuals using either phenolchloroform or the E.Z.N.A. Tissue DNA Kit (Omega Bio-Tek), and obtained COI (Astrin and Stüben 2008), 18S (Hillis and Dixon 1991), ITS1 (Cerca et al. 2020a), and 16S (Palumbi et al. 1991; Zanol et al. 2010) sequences using PCR. Amplified genetic markers were sequenced by

127 Sanger-sequencing at Macrogen-Europe. For detailed information on amplification, primer 128 sequences and extraction please see Cerca et al. (2020b, a). 


\section{Library preparation and Illumina sequencing}

130

131

132

133

134

135

136

137

138

139

140

141

142

143

144

145

146

147

148

149

150

151

152

153

154

155

156

157

We selected 50 Stygocapitella josemariobrancoi, 47 S. subterranea and 24 S. westheidei for library preparation (Supplementary Table 2). Due to the reduced body size, DNA extractions of Stygocapitella yield low concentrations of DNA, therefore, to overcome this problem, we used a combination of whole genome amplification (WGA) (Golombek et al. 2013; de Medeiros and Farrell 2018) followed by a double-digestion Restriction site-Associated DNA sequencing protocol (ddRAD) (Baird et al. 2008; Peterson et al. 2012). To complete the WGA reaction, DNA of a single individual is first denaturated and mixed with random hexamer primers and the Phi29 DNA polymerase (Illustra Genomiphi HY DNA Amplification Kit; GEC Healthcare Life Science). Following the manufacturer's instructions, $2.5 \mu 1$ of template DNA were mixed with $22.5 \mu 1$ of sample buffer, and incubated at $95^{\circ} \mathrm{C}$ for three minutes for denaturation. After this, we added $22.5 \mu 1$ of reaction buffer and $2.5 \mu 1$ of enzyme mix to the DNA-sample buffer solution, incubated the solution at $30^{\circ} \mathrm{C}$ for four hours for DNA amplification and an enzyme heatinactivation at $65^{\circ} \mathrm{C}$ for ten minutes. DNA was purified using AMPure XP beads, and resuspended in $\mathrm{ddH}_{2} \mathrm{O}$. The concentration of the amplified DNA was determined with Qubit and the fragment size distribution with a fragment-analyzer.

For each individual, $500 \mathrm{ng}$ of amplified DNA was digested in $25 \mu 1$ including $0.5 \mu 1$ of each restriction enzyme (Pst-I HF and Mse-I, each 20 units/ $\mu 1$ ) and $2.5 \mu 1$ Cut-smart buffer. The digestion reaction was carried out at $37^{\circ} \mathrm{C}$ for two hours. Digested DNA was purified using

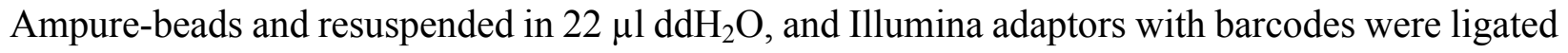
to the digested DNA in a $25 \mu 1$ reaction including $20.5 \mu 1$ sample DNA, $1 \mu 1$ T4 DNA-ligase, 2.5 $\mu 1$ 10X T4 ligase buffer and $1 \mu 1$ adapter P1/2-mix. This reaction was incubated for 30 minutes at $25^{\circ} \mathrm{C}$, and the enzyme inactivated for 10 minutes at $65^{\circ} \mathrm{C}$. The barcoded libraries were pooled, cleaned using AMPure XP beads, and eluted in $100 \mu \mathrm{l}$ of ultra-purified water. We ran a sizeselection step using Blue Pippin's 100-600 bp cassette (BDF2010) selecting for fragment-length between 300-600 bp followed by cleaning with AMPure XP beads to remove short fragments. The library was amplified in $200 \mu 1$ including $100 \mu \mathrm{l}$ Q5 HiFi MasterMix, $5 \mu 1$ Primer mix and $20 \mu 1$ DNA, in 18 PCR cycles (initial denaturation: $98^{\circ} \mathrm{C}$ for $30 \mathrm{~s}$; 18 cycles of $98^{\circ} \mathrm{C}$ for 10 seconds, $60^{\circ} \mathrm{C}$ for 15 seconds, $72^{\circ} \mathrm{C}$ for 15 seconds; and a final elongation of $72^{\circ} \mathrm{C}$ for 2 minutes). Finally, two 
158 cleaning-quantification steps using AMPure XP beads were done, and the libraries were sent for

159 Illumina Sequencing on an Illumina Hi-Seq 4000.

160 Individual identification and multi-marker phylogeny

161 Raw 16S, 18S, ITS1 and COI sequences were assembled, and ends were automatically 162 trimmed to remove primers and low-quality ends using Geneious v6.8.1, (Supplementary Table 163 2). Each consensus sequence was queried against the default NCBI database (nr/nt) using BLAST 164 (Altschul et al. 1990; Camacho et al. 2009) to exclude potential contamination. For each gene, 165 sequences were aligned using mafft v7.310, using a maximum of 1,000 iterations, and the ends of 166 the sequences trimmed until the first position without missing data. The accurate localpair 167 algorithm was used for all genes (Katoh and Standley 2013), with the exception of ITS1, which 168 had a single peak, where the globalpair algorithm was applied as it is optimized for gappy 169 sequences. The dataset was concatenated using FASconCAT v1.1 (Kück and Meusemann 2010), 170 and a partitioned phylogenetic tree was obtained using IQ-tree v1.6.10, by applying 1,000 171 fastbootstrap replications. Model determination was done automatically by IQ-tree, and it included $172 \mathrm{TIM} 2+\mathrm{I}$ for ITS1, JC+I for 18S, TN+R2 for 16S and HKY+I for COI. The congruence between 173 these genes, and in the individuals used has previously been determined in Cerca et al. (2020b, a).

174

175

176

177

178

179

180

181

182

183

184

185

\section{De novo RAD assembly}

All bioinformatic work is available in https://github.com/jcerca/Papers/tree/main/Stygocapitella_PeerJ . Since no reference genome is available for Stygocapitella, we used the de novo assembly approach implemented in Stacks v2.2 to identify RAD loci (Rochette and Catchen 2017; Rochette et al. 2019). The first module of Stacks, 'process_radtags', was executed using flags tailored to improve data quality (--clean, -quality, --rescue). To optimize Stacks' parameters, we ran the de novo pipeline repeatedly using different -M (mismatch between stacks within individuals) and -n (mismatches between stacks between individuals) values, as suggested by best practices (Paris et al. 2017). The total number of loci resulting from different $-\mathrm{M}$-n values were plotted and analyzed, selecting -M 3 and -n 3 for the final dataset. Populations, as required for the population map, were defined based on the species and sampling site (total of 22 populations - Supplementary Table 1). 
Since we observed a considerably high level of missing data in the dataset $(>90 \%$ missing

187

188

189

190

191

192

193

194

195

196

197

198

199

200

201

202

203

204

205

206

207

208

209

210

211

212

213

214

215 data), we tested and implemented a new method to improve RADseq datasets. Missing data is especially problematic in RADseq as it can lead to erroneous inference of population-genetic parameters (Arnold et al. 2013; Gautier et al. 2013; Hodel et al. 2017). However, applying stringent filtering for missing data has been shown to prune parsimonious-informative loci, with bestpractices suggesting non-conservative pruning of the data (Huang and Lacey Knowles 2016; Lee et al. 2018; Crotti et al. 2019). To mitigate missing data while avoiding stringent filtering, we applied a novel procedure, which allowed us to retrieve more loci from our data (Cerca et al submitted). In brief, we ran Stacks for every population present in the population map - 22 times in total (Supplementary Table 1) - thus lowering phylogenetic distance in the dataset. Since phylogenetic distance (biological origin) and artefacts in generating and processing data can lead to allelic dropout (O’Leary et al. 2018), lowering phylogenetic distance will isolate dropout caused by artefacts in library preparation (e.g. DNA size-selection, low DNA concentrations, poor digestion), and loss of information due to whole genome amplification (de Medeiros and Farrell 2018). For each population, we identified samples with $>45 \%$ missing loci and removed these from a final analysis (hereafter the clean dataset). To evaluate how the optimization impacted the final number of loci we compared the number of loci and missingness in the dataset before cleaning (hereafter the uncleaned dataset) and in the cleaned dataset using the values of -r 25 (a locus has to be present in at least $25 \%$ of individuals comprising a population to be considered) and -p 4 (a locus has to be present in at least 4 populations to be considered). Finally, we included a technical replicate in the dataset (individuals 22201 and 222 01R), and checked whether it was coherently placed in all the analyses.

\section{Population genomics and phylogenomics}

From the clean dataset, we extracted a single nucleotide polymorphism-only dataset (SNPs; hereafter variant dataset) and an all-sites dataset (containing non-variant and variant positions; hereafter all-sites dataset). Separating the data in these two datasets is necessary to meet the assumptions of some statistical tests which may require the presence of non-variant positions to calculate ratios of variant and non-variant sites. The variant dataset was pruned by selecting -r 50 (a locus has to be present in at least 50\% of individuals comprising a population), and -p 8 (a locus has to be part in at least 8 populations) as loci cut-offs, using the 'populations' program included 
216 in Stacks, resulting in 4,737 RAD-loci. After this initial round of cleaning, we used vcftools

217 v0.1.13 (Danecek et al. 2011) to further prune the dataset for 5\% minimum allele frequency (-218 maf), and for mean loci coverage values between 10-100 (--min-meanDP 10 --max-meanDP 100) 219 and removed 12 individuals which had missingness above $>90 \%$ (--missing-indv; Supplementary 220 Table 2). The combination of coverage filters together with the $-\mathrm{M}-\mathrm{m}$ optimization procedure mentioned above optimizes the generation of RADseq loci by removing loci which may artificially

222

223

224

225

226

227

228

229

230

231

232

233

234

235

236

237

238

239

240

241

242

243

244

245

246 come together (i.e. repetitive regions). Finally, to decrease the effect of physical linkage in the data, we used a custom BASH shell script which kept only one polymorphism (SNP) per RAD locus, resulting in a final dataset of 3,428 SNPs. Using this dataset, we assessed genetic variation by means of a principal component analysis (PCA), a multi-dimensional scaling (MDS) analysis and an ADMIXTURE analysis. PCA and MDS are model-free approaches to estimate population structure, being complementary as PCA assumes 'mean values' for missing data (i.e. dragging individuals with high missingness to the center) whereas MDS does not. PCA was computed using the R package Adegenet (Jombart and Ahmed 2011) and MDS with plink v1.9 (Chang et al. 2015). ADMIXTURE is a model-oriented approach to determine population structure based on the presence/absence of heterozygotes (Alexander et al. 2009). We ran ADMIXTURE assuming 1-6 clusters $(\mathrm{K})$, running a total of 5 replicates for each $\mathrm{K}$, and determined the best $\mathrm{K}$ by estimating the cross-validation error (Supplementary Figure 1). Considering the potential for admixture of individuals in sympatry (Figure 1), we used $f 3$ statistics, included as part of the Admixtools package, as a direct test for detecting hybridization (Patterson et al. 2012; Peter 2016). These statistics consists of a 3 populations test where a focal population is derived from admixture between the other two populations. When this score is negative, it suggests that admixture likely has occurred. We estimated errors and confidence intervals on the $f 3$ statistics by partitioning the dataset into blocks and applying a jackknife bootstrapping. Finally, we inferred species-level divergence by estimating Weir and Cockerham's $F_{\text {ST }}$ using veftools (Weir and Cockerham 1984; Danecek et al. 2011).

The all-sites dataset was obtained by extracting FASTA sequences from Stacks. To run the phylogenomic analysis, we wrote a Perl script to reorganize the data into loci, concatenated all loci in a supermatrix using FasConCat-G (Kück and Longo 2014) and ran a partitioned-tree using IQtree v1.6.10 (Nguyen et al. 2015) specifying 1,000 fast bootstrap replications (Chernomor et al. 2016; Hoang et al. 2017), and locus-specific models which were determined as part of the run 
247 (Kalyaanamoorthy et al. 2017). To explore the effect of missing data on the tree topology, we ran

248 BaCoCa (Kück and Struck 2014), a pipeline which provides summary-level statistics on the 249 concatenation matrix and tree, such as the \% of positions with missing data shared by a pair of 250 individuals. Pairwise positive overlap values were plotted to the tree topology using the R package 251 ape (Paradis and Schliep 2018). Additionally, we ran an Unweighted Pair Group Method with 252 Arithmetic mean (UPGMA) tree using only the average \% of pairwise shared data per individual 253 (i.e. pairwise percentage of shared data between taxa which do not have an indel, ambiguous 254 character state, or a missing character state). The UPGMA tree was run to understand whether taxa were grouped based on the overall pattern of missing data. Additionally, since RADseq loci

256

257

258

259

260

261

262

263

264

265

266

267

268

269

270

271

272

273

274

275

276 (represented by allele 0 and allele 1 ) are not phased and since the labelling of 0 and 1 are arbitrary, we obtained a consensus sequence for each individual. This was done by running the consambig (consensus ambiguous) module included in the EMBOSS pipeline (Rice et al. 2000). We did a species network analysis using SPLITSTREE v4 (Huson and Bryant 2006) to complement phylogenetic inference since the network does not enforce dichotomous branching at each node.

To gauge population-level patterns and diversity, we selected loci from the all-sites dataset without missing-data at the population-level and estimated summary statistics including nucleotide diversity $(\pi)$, Waterson's estimator of genetic diversity $(\mathrm{S})$ and Tajima's D using DNAsp v6 (Rozas et al. 2017). This dataset was not pruned for minimum allele frequency. The selection of sites without missing data is grounded on best-practices as missing data can lead to the under- or overestimation of some of these parameters (Arnold et al. 2013). Importantly, we selected only populations where 3 or more individuals (i.e. $>5$ 'chromosomes') had data available (Supplementary Table 2).

Finally, we evaluated various demographic scenarios using fastsimcoal2, using the same dataset for the previous analysis which included running fastsimcoal2 (Excoffier et al. 2013). Fastsimcoal2 uses the site-frequency spectrum (SFS) and a coalescent-simulation framework based on an arbitrary user-defined scenario to infer population sizes, strength of gene flow and times of coalescence. To assess these models we calculated AIC and likelihood. Likelihood is calculated by running the 'best parameters' for each specified scenario multiple times and obtaining the distribution of likelihood estimates. AIC was calculated using a script available in https://speciationgenomics.github.io/fastsimcoal2/. To implement these simulations, we used the 
277 phylogeny obtained with Stygocapitella subterranea and $S$. westheidei as sister species, and $S$.

278 josemariobrancoi as sister to the remaining two. We defined the following models: no gene flow, 279 ancient gene flow (i.e. between Stygocapitella josemariobrancoi and the stem lineage of $S$. 280 subterranea and $S$. westheidei), geographic gene flow (i.e. similar as the ancient gene flow, but 281 also with modern gene flow between the sympatric Stygocapitella subterranea and $S$. 282 josemariobrancoi; note we refer to 'modern' as opposed to 'ancient', that is, in existing lineages), 283 modern gene flow (gene flow between all three modern species), all gene flow (gene flow between 284 all three species and the two ancestral lineages), modern gene flow only between $S$. 285 josemariobrancoi and S. subterranea, modern gene flow only between $S$. josemariobrancoi and $S$. 286 westheidei, modern gene flow only between $S$. westheidei and S. subterranea, gene flow in 287 ancestral times and between $S$. subterranea and $S$. westheidei, and ancient gene flow and modern 288 gene flow between $S$. josemariobrancoi and $S$. westheidei. When included in the model, gene flow 289 was moduled as asymmetric. Each model was run 10,000 times with an assumed mutation rate of $2901.2 \mathrm{e}-8$, and the best fitting scenario was evaluated using likelihood, by running it 100 times.

291

292

293

294

295

296

297

298

299

300

301

302

303

304

305

\section{Results}

\section{Tree of selected molecular markers}

We compiled a dataset comprising 4,147 bp (the COI fragment consisted of $629 \mathrm{bp}, 16 \mathrm{~S}$ of $548 \mathrm{bp}$, ITS1 of 1,150 and 18S of 1,817 bp), from which 716 sites were phylogenetic-informative sites. From a total of 69 individuals, we obtained $6716 \mathrm{~S}$ sequences, $61 \mathrm{COI}$ sequences, $2818 \mathrm{~S}$ sequences and 31 ITS1 sequences. Every species was recovered as monophyletic (Figure 2 A) with bootstrap support values of 100 for S. josemariobrancoi, of 86 for S. subterranea and of 100 for $S$. westheidei (Figure 2 A). The retrieved tree topology includes $S$. westheidei and S. subterranea as sister species. Stygocapitella josemariobrancoi as sister to the clade comprising S. subterranea and $S$. westheidei. Single gene trees show concordance between markers (Supplementary Figures 2-5)

\section{Genomic dataset}

We obtained a total of $1,277,919,764 \square$ sequencing reads from two Illumina HiSeq4000 lanes. After demultiplexing and cleaning the data with process_radtags, we retained 899,112,800 $\square$ reads $(107,830,588$ reads were discarded for having ambiguous barcodes, 270,174,154 $\square$ for 
306

307

308

309

310

311

312

313

314

315

316

317

318

319

320

321

322

323

324

325

326

327

328

329

330

331

332

333

334

335

ambitious RADtags, and $802,222 \square$ for low quality). When comparing the clean and unclean dataset, the approach to lower allelic dropout yielded a substantial increase of the number of loci. In detail, after running Stacks for each population individually, we removed 17 S. subterranea out of a total of 47, $7 \mathrm{~S}$. westheidei out of 24 , and 16 out of 50 for $S$. josemariobrancoi (roughly $\sim 33 \%$ of the dataset, Supplementary Table 2). The uncleaned dataset yielded 179,742 loci $(55,037,190$ sites including 628,031 variant sites), whereas the cleaned data yielded 368,696 loci $(112,725,106$ sites including 1,100,431 variant sites). When pruned with common denominators included in the module Populations (-r 50 -p4), the unclean dataset yielded 109,369 loci, and the cleaned yielded 272,134 loci. Individual-level missing data was reduced from $84.89 \%$ in the uncleaned dataset to $80.79 \%$ in the cleaned dataset. We validated this approach by comparing PCA, MDS and phylogenomic trees using both cleaned and the uncleaned dataset (see https://ecoevorxiv.org/47tka). A comprehensive investigation of this strategy including additional datasets will be published in a separate paper (Cerca et al. submitted).

\section{Genomic trees and networks}

The phylogenomic tree (Figure 2C) shows a slightly different topology from the tree obtained with selected molecular markers. The branches representing Stygocapitella subterranea, S. westheidei, and $S$. josemariobrancoi have a bootstrap support of 93, 99 and 100, respectively. The tree topology is broadly similar to the selected marker phylogenetic tree, with $S$. josemariobrancoi being sister to the clade comprising $S$. subterranea and $S$. westheidei. However, strictly speaking, none of the species is recovered as monophyletic, since three individuals identified as $S$. josemariobrancoi are not placed with $S$. josemariobrancoi. Specifically, 42204 from Bristol Channel nests within S. subterranea, 42205 from Bristol Channel nests within $S$. westheidei and 40103 from St. Efflam is positioned as sister to S. subterranea (Figure 2C, individuals denoted by arrows). Importantly, mapping of shared pairwise data in the tree topology suggests that these trends are not driven by missing data, since the branches representing the three aforementioned individuals do not exhibit elevated levels of missing data (Figure 2C). The UPGMA tree, which is solely built on a pairwise matrix of missing-data, shows that $S$. subterranea and $S$. josemariobrancoi are generally separated, interlaced by individuals from $S$. westheidei (Supplementary Figure 6). While this suggests that the three species have different amounts of missing data, the fact that individuals are generally mixed suggests that missing data is not driving 
336 phylogenetic reconstruction. For example, the three individuals resulting in a paraphyletic 337 reconstruction are not placed closely to their sister taxa in the tree, therefore indicating that missing 338 data has no influence in the paraphyletic position of these individuals (Supplementary Figure 6). 339 Finally, the generated phylogenomic consensus tree shows a similar topology to the that in Figure 3402 (Supplementary Figure 7). The three samples causing paraphyly of the lineages in the 341 phylogenomic tree are placed within S. subterranea (Bristol Channel 422 04), as sister to the 342 lineage $S$. josemariobrancoi and $S$. westheidei (St. Efflam 40103 ), and as the first branch of $S$. 343 josemariobrancoi (Bristol Channel 422 05).

In the phylogenetic network, Stygocapitella westheidei is separated from the remaining two species, occupying a separate and relatively compact area of the network. Stygocapitella subterranea is mostly confined to one small section of the network, however, three individuals are very close to the center of the network (398 04, 39808 and 39809 from Keitum; Figure 3). In line with the results from the phylogenomic tree, Bristol Channel 422 04, which is identified as part of S. josemariobrancoi, is nested within $S$. subterranea in the network. Stygocapitella josemariobrancoi, on the other hand, is clearly stretched and set apart in the network, occupying a large area (Figure 3). While most individuals are nested within a condensed and remote portion of the network, the individuals Bristol Channel 422 05, St Efflam 40103 and 40104 lie in an intermediate position between the center of the network and the majority of individuals from $S$. josemariobrancoi (Figure 3). This is broadly in agreement with the phylogenomic tree, which shows Bristol Channel 42205 nested with S. westheidei (Figure 2C) and St. Efflam 40103 sister to $S$. subterranea (Figure 2C). The distance between most individuals belonging to $S$. josemariobrancoi and the rest of the network (centre of the network, and the two remaining species) suggests there is a greater degree of differentiation in this species.

Population structure, differentiation and summary statistics

The PCA separates the three species across the first two principal components, (which together explain $30.4 \%$ of the variance; Figure $4 \mathrm{~A}$ ). Three individuals stand out, including Bristol Channel 42204 (labelled as S. josemariobrancoi) which is placed closely with S. subterranea individuals, Bristol Channel 42205 which occupies an intermediate position between $S$. westheidei and $S$. josemariobrancoi, and Lubec 42802 which is relatively distant from the remaining $S$. westheidei individuals. The multi-dimensional scaling plot, which is less affected by missing data, 
366 separates the species into three distinct clusters (MDS; Figure 4B). In coherence with the previous 367 analyses, we detect several taxa with intermediate positions: Bristol Channel 42204 (labelled as $368 S$. josemariobrancoi) is closer to the S. subterranea cluster than to the S. josemariobrancoi; 369 Hoernum 16909 (labelled as S. josemariobrancoi) in an intermediate position between these two 370 species; Bristol Channel 422 05, St. Efflam 401 04, 401 03, 40105 (all labelled as $S$. josemariobrancoi) are found in an intermediate position between $S$. josemariobrancoi and $S$.

372 westheidei; Lubec 42902 (labelled as $S$. westheidei) is also distant from the $S$. westheidei cluster, being relatively close to Bristol Channel 42205 (Figure 4B).

The ADMIXTURE analysis confirms shared genetic signal among species. The most supported cluster size was $K=3$ (Supplementary Figure 1) and is plotted in Figure 5. In agreement with the phylogenetic network, the MDS and the PCA, $S$. westheidei is the species with the least amount of admixture, with only 2 individuals sharing a relatively low degree of ancestry with $S$. subterranea. A majority of $S$. subterranea individuals (17 out of 30) share genetic variation with S. josemariobrancoi. S. josemariobrancoi has 5 individuals which are admixed from $S$. westheidei, and an individual (Bristol 422 04) identified as having a S. subterranea ancestry. Notably, individuals from sympatric areas and belonging to $S$. josemariobrancoi and $S$. westheidei (Hausstrand, Musselburgh, Lubec) show no signal of shared ancestry. However, five $S$. subterranea individuals with shared ancestry belong to two sympatric sites (Hausstrand and Musselburgh). $f 3$ statistics were positive, thus suggesting that the observed patterns of admixture are unlikely to be due to recent admixture (Table 1). Notably, two out of three scenarios retrieved Z scores $>3$ (threshold used for significance), including S. subterranea and S. josemariobrancoi as source and $S$. westheidei as target, and $S$. josemariobrancoi and $S$. westheidei as sources and $S$. subterranea as target.

Notably, $\mathrm{F}_{\mathrm{ST}}$ estimates among species are high, thus indicating isolation. Pairwise $\mathrm{F}_{\mathrm{ST}}$ comparisons were lower between $S$. josemariobrancoi and either of the remaining species: 0.53 for $S$. josemariobrancoi vs $S$. subterranea, 0.492 S. josemariobrancoi vs $S$. westheidei and 0.664 for S. subterranea vs S. westheidei (Table 2).

Summary statistics suggest that populations of $S$. josemariobrancoi have a higher degree of genetic variation. Waterson's estimate, S, ranges between 2.11-2.39 in S. subterranea and between 1.81-2.35 in S. westheidei, and between 1.89-6.83 in S. josemariobrancoi, with Bristol 
396 Channel $(\mathrm{S}=4.92)$, and Gravesend $(\mathrm{S}=6.93$; Table 3). This is similar when analysing nucleotide 397 polymorphisms $(\pi)$, with $S$. subterranea ranging between $0.002-0.0037, S$. westheidei between 398 0.0021-0.0034, but S. josemariobrancoi ranging between 0.0026-0.0099 again with Gravesend and 399 Bristol Channel as outliers (Gravesend $\pi=0.0099$, Bristol Channel $\pi=0.0086$; Table 3). 400 Interestingly, the sympatric sites do not reveal any signal of higher polymorphism, as it would be 401 expected in scenarios of on-going hybridization. For instance, $\pi=0.0033$ and $\mathrm{S}=2.13$ for $S$. 402 subterranea in Musselburgh, and $\pi=0.0045$ and $\mathrm{S}=2.49$ for $S$. josemariobrancoi in Musselburgh. Hausstrand, for which we were only able to obtain data for $S$. josemariobrancoi retrieved a $\pi=$ 404 0.0038 and $\mathrm{S}=2.55$, while the population Lubec of $S$. westheidei shows $\pi=0.0029$ and $\mathrm{S}=2.15$. Tajima's D excludes the possibility for bottlenecks, as none of the populations exhibits significant 406 Tajima's D (i.e. values below -2 or above +2 ; Table 3).

Simulation of demographic scenarios suggests admixture may have happened in ancestral branches (Figure 6). All the best supported scenarios are provided in https:/github.com/jcerca/Papers/blob/main/Stygocapitella PeerJ/11 fscScenarios/ and as supplementary. Three of the top four most supported scenarios using likelihood suggest ancient admixture: geographic gene flow (i.e. gene flow between the two ancestral branches and afterwards between $S$. subterranea and $S$. josemariobrancoi), ancient gene flow (i.e. gene flow between the two ancestral branches), ancient gene flow and between western lineages (i.e. gene flow between the two ancestral branches and afterwards between $S$. westheidei and $S$. josemariobrancoi). The remaining scenario suggests no gene flow. The most supported of these scenarios was the geographic gene flow, which includes coalescent times of 411,402 generations for the first coalescent event (presumably, Stygocapitella has a generation time of a single year), and 21,680,033 for the second coalescent event. The ancient gene flow scenario, which was the second most supported, includes estimates of 585,534 generations for the first coalescent event and $16,749,615$ generations for the second coalescent event. The no gene flow scenario is the $3^{\text {rd }}$ most supported scenario, but the first and second coalescent events are suggested to have occurred 451 and 12,834 years ago, being clearly at odds with previous evidence suggesting these lineages

423 diverged millions of years ago (Struck et al. 2017; Cerca et al. 2020a). The fourth most supported 424 scenario, ancient gene flow and gene flow between western lineages, has coalescent times of 425 3,566,294 and 18,353,555 (Figure 6). Finally, while the AIC assessment provide slightly different 
426 results (Supplementary Figure 8), the second and third most supported scenarios are the geographic

427 gene flow and ancient gene flow; being thus in agreement with the likelihood results.

\section{Discussion}

Morphological similarity through extended periods of times, or stasis, has been hypothesized to occur under three possible scenarios underlied by genetics: homogenous genetic variation (due to e.g. ILS, hybridization), genetic constraints (e.g. pleiotropy), and lack of genetic variation (e.g. bottlenecks and founder effects) (Futuyma 2010). While our sampling design does not account for genetic constraints, we study the evolutionary history of Stygocapitella species seeking to determine signals of loss of genetic variation or shared genetic variance. We find that the three morphologically similar Stygocapitella species herein studied share genetic variation and exclude the possibility of recent bottlenecks or recent admixture. Demographic and admixture analysis reveal signatures of ancestral admixture and incomplete lineage sorting during the divergence of these three species. We discuss the possible implications of these processes to the genomic underpinnings of indistinguishable morphology among cryptic species.

\section{Whole genome amplification and the generation of RADseq data}

We show that WGA combined with RAD sequencing may become an important tool for microscopic eukaryote genomics. RADseq library preparation typically requires 200-500 ng of DNA per individual, yet DNA extraction of a single Stygocapitella individual typically yields 10$100 \mathrm{ng}$ of DNA, thus representing a challenge to obtain genome-level data. One potential solution is to pool individuals. However, pooling may not be ideal when dealing with morphologically similar species, especially when they occur in sympatry, as observed in Stygocapitella, since the identification of individuals based solely on morphology may be impossible. Arguably, one of the major advantages of RADseq is to open up population genomics and phylogenomics as approaches for non-model systems at an affordable cost. In such systems, experimental designs may benefit 450 from the inclusion of the largest number of individuals possible, which encompass the whole spectrum of populations or species to determine species boundaries, phylogeography, population structure and the phylogeny. Pooling individuals from different species or populations together may lead to an incorrect inference of the phylogeny when species boundaries are not known, but 
455 data processing and interpretation, and may require extra efforts such as barcoding of individuals

456 before pooling. In the view of these challenges, we optimized and applied a whole-genome 457 amplification protocol to obtain genome level data, thus confirming its potential for population 458 genomic-inference and phylogenetics (de Medeiros and Farrell 2018, 2020).

\section{Bottlenecks, meiofaunal dispersal and morphological similarity}

460

461

462

463

464

465

466

467

468

469

470

471

472

473

474

475

476

477

478

479

480

481

482

483

484

The few phylogeographic studies available for meiofaunal organisms have generally detected founder effects and bottlenecks, and have discussed how colonization dynamics may be determined by a series of bottlenecks (Casu and Curini-Galletti 2006; Derycke et al. 2007; Andrade et al. 2011), however, we find no evidence for bottlenecks in this dataset when using summary statistics and Tajima's D. Evidence for the prevalence of bottlenecks in meiofauna has been further supported by experimental evidence which showed that colonization of new areas may be characterized by founder effects and bottlenecks, which, in turn, are expected to shape the genetic differentiation of meiofaunal populations (Derycke et al. 2007, 2013). Broadly, this follows hypotheses on marine-invertebrate biogeography which suggests that repeated extinction and recolonization dynamics may be involved in shaping genetic differentiation in populations and species (Andrade et al. 2011; Derycke et al. 2013). We find no indication of bottlenecks in Stygocapitella, as suggested by non-significant Tajima's D values (Table 3), even though that part of the sampling distribution of Stygocapitella included areas which were glaciated only 10,000 years ago (Wares and Cunningham 2001). Two possibilities may explain this scenario and support our findings. First, the hypothesis that meiofauna disperse through a series of bottlenecks may require more evidence. Indeed, when scoring a total of 752 papers, we could only detect 48 studies focusing on biogeography and 7 on evolutionary biology (including population genetics) (Cerca et al. 2018), thus suggesting that meiofaunal biogeography is in its early days and more studies are needed for more solid conclusions. This hypothesis may also be at odds with evidence that meiofauna may be, indeed, good dispersers (reviewed in Cerca et al. 2018). Even if dispersal is carried by only a limited group of individuals, concomitant with the idea of a founder effect and bottleneck colonization, the dispersal of more organisms from 'source populations' (multiple waves of dispersal) through time would eventually homogenize genetic variation in newly colonized areas. Second, to the best of our knowledge, this is the first work to focus on populationgenomic level data in meiofauna. Typically, works have focused on sequencing a limited 
485

486

487

488

489

490

491

492

493

494

495

496

497

498

499

500

501

502

503

504

505

506

507

508

509

510

511

512

513

514

combination of mitochondrial and nuclear genes (e.g. (Derycke et al. 2005, 2007, 2008; Kieneke et al. 2012; Leasi and Norenburg 2014). While non-recombining data, such as mitochondrial markers, may provide an ideal indication for the occurrence of bottlenecks, these effects should be confirmed on complementary genomic regions. For instance, using the $16 \mathrm{~S}$ mitochondrial marker, we previously detected single haplotypes in populations of $S$. subterreanea or $S$. josemariobrancoi. These populations had a statistically significant Tajima's D ( $S$. josemariobrancoi individuals from Bristol Channel; S. subterranea individuals from Glenancross) (Cerca et al. 2020b). While this pattern was in conflict with that of the nuclear ITS1 (Cerca et al. 2020a), it is further rejected when using genome-level data, which provides a more comprehensive, and independent, assessment of genomic variance. This suggests that the dispersal-by-bottlenecks idea in meiofauna warrants more data, and that biogeography of meiofauna will benefit from more genomic studies.

Overall, we suggest that morphological similarity in Stygocapitella is unlikely to result from the lack of standing genetic variation due to re-occurring bottlenecks. Under this hypothesis, it is expected that bottlenecks reduce genetic variation, which will in turn limit morphological evolution, thus leading to stasis (Futuyma 2010). Given the lack of evidence for recent bottlenecks in Stygocapitella, this does not seem plausible. In addition to the evidence for the lack of recent bottlenecks, the fact that the remaining 8 Stygocapitella species live in similar habitats and are distributed throughout the world (Cerca et al. 2020a) indirectly suggests that bottlenecks may not be typical in the evolutionary history of the group.

\section{Evidence for Incomplete Lineage Sorting and Admixture}

We find clear evidence for shared genetic variation in Stygocapitella. The most conspicuous evidence for this comes from the admixture analysis, which clearly demonstrates admixed populations in the three species (Figure 5). This evidence is further supported by individuals with intermediate positions in the MDS - a test which is robust to missing data (Figure 4). However, several evidences do not support a preponderant role of recent admixture. First, we obtained no evidence for admixture when using F-statistics, since we find only positive F-values (Table 1). Second, contrary to the expectation of ongoing gene flow, we do not observe higher levels of heterozygosity in sympatric populations (Lubec in the USA, Musselburgh in Scotland, Hausstrand in Germany; Table 3) where individuals of different species are found in the same sediment sample in close proximity (volume ranging from $50-500 \mathrm{~cm}^{3}$ ). Third, admixture often 
515 generates incongruence between mitochondrial and nuclear markers (Melo-Ferreira et al. 2012; 516 Sloan et al. 2017), which is not seen in single-marker trees (Supplementary Figures 2-5). Fourth, 517 models with exclusive recent admixture are generally poorly supported by the demographic 518 analysis (Figure 6). In contrast, three out of the four most supported demographic scenarios suggest 519 ancient admixture, and one supported no gene flow at all (Figure 6). The scenario with no gene 520 flow inferred coalescent times of 451 and 13,834 generations or years ( 1 generation is expected to 521 be 1 year, Günter Purschke pers. comm)] which are not compatible with estimates of the splitting 522 age of the three Stygocapitella species ( 5-30 million years ago; Cerca et al. 2020b). Given that 523 reduced times of coalescence are a typical signature of simulations that do not account for gene 524 flow, when it has occurred in empirical data (Leaché et al. 2019), it is likely that incomplete lineage 525 sorting alone cannot explain the patterns of shared variation among Stygocapitella species. In other 526 words, the demographic analysis supports a scenario that includes ancient admixture. The three 527 scenarios with ancient admixture vary in the presence or absence of admixture after the second 528 coalescence event ( $S$. subterranea and $S$. josemariobrancoi): in one scenario, admixture is 529 exclusive to the ancestral branch; in the remaining two, gene flow between $S$. josemariobrancoi 530 and either $S$. westheidei or S. subterranea occur. Given the lack of support for on-going gene flow 531 between species by the $\mathrm{F}_{\mathrm{ST}}$, summary statistics, and F-statistics (Tables 1-3, Supplementary 532 Figures 1-5), admixture may have occurred immediately before or after the speciation event of $S$. 533 westheidei or S. subterranea, but not in recent times (i.e. the last generations). Furthermore, the 534 occurrence of ancient admixture can affect the inference of recent admixture when not take the 535 phylogeny into account (Malinsky et al. 2018; Ferreira et al. 2020), this may explain the 536 incongruence between some of our analysis. Therefore, while the demographic analysis suggests 537 the occurrence of admixture among $S$. josemariobrancoi and the other species, future studies are 538 necessary to confidently dissect and determine the role of recent gene flow in the system with 539 independent analyses. For example, these studies will benefit from using whole-genome data to 540 determine whether interspecific divergence in regions of the genome show gene-species tree 541 discordance, thereby dissecting ILS and recent hybridization (Joly et al. 2009; Giska et al. 2019). 542 Also, the demographic analysis favouring a preponderant role of ancient admixture does not 543 exclude the occurrence of ILS, and the beforementioned approach would also allow to clarify the 544 relative contribution of ILS and gene flow to shared patterns of variation among species. In sum, 
545 to the extent that we can speculate, our data suggests that shared genetic variance is more likely

546 explained by an evolutionary history including incomplete lineage sorting and ancient geneflow.

547 Evidence for ancient admixture or incomplete lineage sorting is further seen in the 548 phylogenomic analysis. Phylogenetic approaches, which seek to reconstruct the evolutionary 549 history of lineages, often fail to resolve the evolutionary history and the 'true tree-topology' when 550 the taxa in question have high rates of incomplete lineage sorting or admixture (Kubatko and 551 Degnan 2007; Degnan and Rosenberg 2009), but incongruence may also result from tree-building 552 errors, paralogy or horizontal gene transfer (Scornavacca and Galtier 2017). We discard tree553 building errors based on the following evidence. First, individuals with intermediate positions in 554 the PCA and MDS correspond to those causing paraphyly in the trees. Second, when exploring the 555 effects of missing data through a) labelling the tree with \% of missing data (Figure 2); and b) 556 constructing a cladogram based only on the shear \% of missing data (i.e. UPGMA tree, 557 Supplementary Figure 6); we find the placement of intermediate individuals is not guided by 558 missing data. Should missing data determine their placement, we would expect these specimens to 559 nest in close proximity in the UPGMA tree. Finally, in the phylogenetic network, the individuals 560 which are also far removed from the remaining $S$. josemariobrancoi individuals, occupying central 561 positions or being paraphyletic in the phylogenetic network correspond to those paraphyletic in 562 the tree and in intermediate positions in the PCA and MDS.

In sum, incomplete lineage sorting and ancient hybridization are known to contribute to 564 levels of shared variation among species (Pease et al. 2016; Malinsky et al. 2018; Edelman et al. 565 2019), even at deep evolutionary levels (Song et al. 2015; Suh et al. 2015). The development of tools which employ the substantial amount of modern genomic data has allowed separating cases of ILS and ancient admixture, showing that ancient hybridization can have a strong impact in the levels of shared variation among species complexes (Malinsky et al. 2018; Li et al. 2019; Taylor and Larson 2019; Ferreira et al. 2020), even after several million years of divergence (Barth et al. 2020; Suvorov et al. 2020). Future work should employ multispecies-network methods or coalescent simulations (Joly et al. 2009) to determine the relative role of ILS and ancient

572 admixture. However, it does not seem unlikely that both processes might have thus contributed to 573 levels of shared variation across 5-30 millions of the divergence of Stygocapitella (Cerca 2020).

\section{Incomplete lineage sorting and morphological similarity}


The debate on morphological similarity is slowly shifting from 'are cryptic species an

576 artefact of systematics?' to 'what are the causes underlying morphological similarity?', following

577 the evidence that speciation is not necessarily accompanied by morphological divergence (Wada

578 et al. 2013; Swift et al. 2016; Cerca et al. 2020b). We have previously argued that the study of

579 morphological similarity will benefit from predictions, models, and evidence from paleontological

580 stasis (Cerca et al. 2020a), which positions that stasis may result from constraints, selective

581 pressures on physiology and/or behaviour, stabilizing selection, niche conservatism (Hansen and

582 Houle 2004; Estes and Arnold 2007; Futuyma 2010). While similarity in different cryptic species 583 complexes may stem from different causes, morphological similarity in the three studied

584 Stygocapitella species complex is likely associated with homogeneous genetic variation caused by 585 incomplete lineage sorting and ancestral admixture that occurred during the divergence of the 586 complex (Futuyma 2010). In such a scenario, it is expected that patterns of genetic variation remain 587 similar for the species, thus resulting in the retention of symplesiomorphic morphological states 588 (Futuyma 2010) and in the deceleration of morphological evolution (Cerca et al. 2020b). In any 589 case, future works using whole-genome data are necessary to, for example, detect if regions 590 affected by incomplete lineage sorting and gene flow are disproportionally enriched for genes that 591 usually contribute for morphological divergence in closely related taxa. These works should also 592 employ more variant-level data to confirm the patterns herein obtained.

\section{Conclusions}

594 The increasing discovery of cryptic species has led to heated debates in systematics, mostly 595 lacking an integration in an evolutionary framework. Here, we tested the hypotheses that 596 morphological similarity may own to reduced genetic variation (bottlenecks, founder effects), 597 recent admixture (shared genetic variation), or incomplete lineage sorting and ancient admixture. 598 We found that morphological similarity in the three morphologically similar Stygocapitella species 599 may own to incomplete lineage sorting or ancient admixture underlying shared genetic variation. 600 Future works should focus on understanding whether reduced genetic variation or shared genetic 601 variation underlies morphological similarity in other systems.

\section{Acknowledgements}


JC is grateful to Tim Worsfold, Andy Mackie, Henning Reiss, Lis Jørgensen for laboratory 604 space in the UK and Norway. We thank Audun Schrøder-Nielsen and Lisbeth Thorbek for 605 assistance in laboratory work, and Inês Modesta for fieldwork support. We are grateful to Diego 606 Fontaneto, Gerardo Perez-Ponce de Leon and an anonymous reviewer for their comments, 607 suggestions and critiques, which have led to the substantial improvement of this manuscript. We 608 acknowledge the use of Norwegian national infrastructure for high-performance computing and 609 storage via the projects NN9408K and NS9408K, respectively. Fieldwork was partly supported by 610 a Den Grevelige Hjelmstjerne-Rosencroneske Stiftelse ved UiO (JC), and THS was partly 611 supported by the EU Assemble program. A UiO:LifeScience internationalization support and a 612 Godfrey Hewitt mobility award allowed JC to visit Julian Catchen at the UIUC. JC dedicates this 613 paper to

\section{Author contributions}

615 JCe, MDM, THS designed this study. JCe and THS collected organisms in the field. JCe extracted 616 DNA and prepared RADseq libraries. JCe did data analysis with support of MR (population 617 genomics), JCa (RADseq), AR-C (RADseq), MSF (ILS), and THS (phylogenetics). JCe drafted 618 the manuscript, which was read, commented on and approved by all the remaining authors.

\section{References}

Alexander DH, Novembre J, Lange K (2009) Fast model-based estimation of ancestry in unrelated individuals. Genome Res 19:1655-1664. https://doi.org/10.1101/gr.094052.109

Altschul SF, Gish W, Miller W, et al (1990) Basic local alignment search tool. J Mol Biol 215:403-410. https://doi.org/10.1016/S0022-2836(05)80360-2

Andrade SCS, Norenburg JL, Solferini VN (2011) Worms without borders: Genetic diversity patterns in four Brazilian Ototyphlonemertes species (Nemertea, Hoplonemertea). Mar Biol 158:2109-2124. https://doi.org/10.1007/s00227-011-1718-3

Arnold B, Corbett-Detig RB, Hartl D, Bomblies K (2013) RADseq underestimates diversity and introduces genealogical biases due to nonrandom haplotype sampling. Mol Ecol 22:31793190. https://doi.org/10.1111/mec.12276 
630

631

632

633

634

635

636

637

638

639

640

641

642

643

644

645

646

647

648

649

650

651

652

653

654

655

656

Astrin JJ, Stüben PE (2008) Phylogeny in cryptic weevils: Molecules, morphology and new genera of western Palaearctic Cryptorhynchinae (Coleoptera: Curculionidae). Invertebr Syst 22:503-522. https://doi.org/10.1071/IS07057

Baird NA, Etter PD, Atwood TS, et al (2008) Rapid SNP discovery and genetic mapping using sequenced RAD markers. PLoS One 3:e3376. https://doi.org/10.1371/journal.pone.0003376

Barth JMI, Gubili C, Matschiner M, et al (2020) Stable species boundaries despite ten million years of hybridization in tropical eels. Nat Commun 11:1-13. https://doi.org/10.1038/s41467-020-15099-X

Bernardo J (2011) A critical appraisal of the meaning and diagnosability of cryptic evolutionary diversity, and its implications for conservation in the face of climate change. Clim Chang Ecol Syst 380-438. https://doi.org/10.1017/CBO9780511974540.019

Bickford D, Lohman DJ, Sodhi NS, et al (2007) Cryptic species as a window on diversity and conservation. Trends Ecol Evol 22:148-155. https://doi.org/10.1016/j.tree.2006.11.004

Camacho C, Coulouris G, Avagyan V, et al (2009) BLAST+: Architecture and applications. BMC Bioinformatics 10:1-9. https://doi.org/10.1186/1471-2105-10-421

Casu M, Curini-Galletti M (2006) Genetic evidence for the existence of cryptic species in the mesopsammic flatworm Pseudomonocelis ophiocephala (Rhabditophora: Proseriata). Biol J Linn Soc 87:553-576. https://doi.org/10.1111/j.1095-8312.2006.00588.x

Cerca J, Meyer C, Purschke G, Struck TH (2020a) Delimitation of cryptic species drastically reduces the geographical ranges of marine interstitial ghost-worms (Stygocapitella; Annelida, Sedentaria). Mol Phylogenet Evol 143:106663. https://doi.org/10.1016/j.ympev.2019.106663

Cerca J, Meyer C, Stateczny D, et al (2020b) Deceleration of morphological evolution in a cryptic species complex and its link to paleontological stasis. Evolution (N Y) n/a:1-16. https://doi.org/10.1111/evo.13884

Cerca J, Purschke G, Struck TH (2018) Marine connectivity dynamics: clarifying cosmopolitan distributions of marine interstitial invertebrates and the meiofauna paradox. Mar Biol 
657

658

659

660

661

662

663

664

665

666

667

668

669

670

671

672

673

674

675

676

677

678

679

680

681

682

165:123. https://doi.org/10.1007/s00227-018-3383-2

Chang CC, Chow CC, Tellier LCAM, et al (2015) Second-generation PLINK: Rising to the challenge of larger and richer datasets. Gigascience 4:1-16. https://doi.org/10.1186/s13742015-0047-8

Chenuil A, Cahill AE, Délémontey N, et al (2019) Problems and questions posed by cryptic species. A framework to guide future studies. pp 77-106

Chernomor O, Von Haeseler A, Minh BQ (2016) Terrace aware data structure for phylogenomic inference from supermatrices. Syst Biol 65:997-1008. https://doi.org/10.1093/sysbio/syw037

Crotti M, Barratt CD, Loader SP, et al (2019) Causes and analytical impacts of missing data in RADseq phylogenetics: Insights from an African frog (Afrixalus). Zool Scr 48:157-167. https://doi.org/10.1111/zsc.12335

Danecek P, Auton A, Abecasis G, et al (2011) The variant call format and VCFtools. Bioinformatics 27:2156-2158. https://doi.org/10.1093/bioinformatics/btr330

De León GPP, Nadler SA (2010) What we don’t recognize can hurt us: A plea for awareness about cryptic species. J Parasitol 96:453-464. https://doi.org/10.1645/GE-2260.1

de Medeiros BAS, Farrell BD (2018) Whole genome amplification in double-digest RAD-seq results in adequate libraries but fewer sequenced loci. PeerJ. https://doi.org/10.7717/peerj.5089

de Medeiros BAS, Farrell BD (2020) Evaluating insect-host interactions as a driver of species divergence in palm flower weevils. Commun Biol. https://doi.org/10.1038/s42003-02001482-3

Degnan JH, Rosenberg NA (2009) Gene tree discordance, phylogenetic inference and the multispecies coalescent. Trends Ecol Evol 24:332-340. https://doi.org/10.1016/j.tree.2009.01.009

Derycke S, Backeljau T, Moens T (2013) Dispersal and gene flow in free-living marine 
684

685

686

687

688

689

690

691

692

693

694

695

696

697

698

699

700

701

702

703

704

705

706

707

708

709

Derycke S, Remerie T, Backeljau T, et al (2008) Phylogeography of the Rhabditis (Pellioditis) marina species complex: Evidence for long-distance dispersal, and for range expansions and restricted gene flow in the northeast Atlantic. Mol Ecol 17:3306-3322. https://doi.org/10.1111/j.1365-294X.2008.03846.x

Derycke S, Remerie T, Vierstraete A, et al (2005) Mitochondrial DNA variation and cryptic speciation within the free-living marine nematode Pellioditis marina. Mar Ecol Prog Ser 300:91-103. https://doi.org/10.3354/meps300091

Derycke S, Vynckt R Van, Vanoverbeke J, et al (2007) Colonization patterns of Nematoda on decomposing algae in the estuarine environment: Community assembly and genetic structure of the dominant species Pellioditis marina. Limnol Oceanogr 52:992-1001. https://doi.org/10.4319/10.2007.52.3.0992

Dornburg A, Federman S, Eytan RI, Near TJ (2016) Cryptic species diversity in sub-Antarctic islands: A case study of Lepidonotothen. Mol Phylogenet Evol 104:32-43. https://doi.org/10.1016/j.ympev.2016.07.013

Dufresnes C, Strachinis I, Suriadna N, et al (2019) Phylogeography of a cryptic speciation continuum in Eurasian spadefoot toads (Pelobates). Mol Ecol 3257-3270. https://doi.org/10.1111/mec.15133

Edelman NB, Frandsen PB, Miyagi M, et al (2019) Genomic architecture and introgression shape a butterfly radiation. Science (80- ) 599:594-599

Eldredge N, Gould SJ (1972) Punctuated Equilibria: An alternative to phylogetic gradualism. In: Schopf TJM (ed) Models in paleobiology. Freeman, Cooper and Co., San Francisco., pp $82-115$

Erlank E, Koekemoer LL, Coetzee M (2018) The importance of morphological identification of African anopheline mosquitoes (Diptera: Culicidae) for malaria control programmes. Malar J 17:1-7. https://doi.org/10.1186/s12936-018-2189-5

Estes S, Arnold SJ (2007) Resolving the paradox of stasis: models with stabilizing selection 
710

711

712

713

714

715

716

717

718

719

720

721

722

723

724

725

726

727

728

729

730

731

732

733

734

735

explain evolutionary divergence on all timescales. Am Nat 169:227-244. https://doi.org/10.1086/510633

Ferreira MS, Jones MR, Callahan CM, et al (2020) The legacy of recurrent introgression during the radiation of hares. Syst Biol

Fišer C, Robinson CT, Malard F (2018) Cryptic species as a window into the paradigm shift of the species concept. Mol Ecol 27:613-635. https://doi.org/10.1111/mec.14486

Futuyma DJ (2010) Evolutionary constraint and ecological consequences. Evolution (N Y) 64:1865-1884. https://doi.org/10.1111/j.1558-5646.2010.00960.x

Gautier M, Gharbi K, Cezard T, et al (2013) The effect of RAD allele dropout on the estimation of genetic variation within and between populations. Mol Ecol 22:3165-3178. https://doi.org/10.1111/mec.12089

Giska I, Farelo L, Pimenta J, et al (2019) Introgression drives repeated evolution of winter coat color polymorphism in hares. Proc Natl Acad Sci U S A 116:24150-24156. https://doi.org/10.1073/pnas.1910471116

Golombek A, Tobergte S, Nesnidal MP, et al (2013) Mitochondrial genomes to the rescue Diurodrilidae in the myzostomid trap. Mol Phylogenet Evol 68:312-326

Gould SJ (2002) The structure of evolutionary theory

Hansen TF, Houle D (2004) Evolvability, stabilizing selection, and the problem of stasis. In: Pigliucci M, Preston K (eds) Phenotypic integration: studying the ecology and evolution of complex phenotypes. Oxford University Press, New York, pp 130-154

Hillis DM, Dixon MT (1991) Ribosomal DNA: Molecular evolution and phylogenetic inference. Q Rev Biol 66:411-453

Hoang DT, Chernomor O, von Haeseler A, et al (2017) Ufboot2: Improving the ultrafast bootstrap approximation. 35:518-522. https://doi.org/10.5281/zenodo.854445

Hodel RGJ, Chen S, Payton AC, et al (2017) Adding loci improves phylogeographic resolution in red mangroves despite increased missing data: Comparing microsatellites and RAD-Seq 
736

737

738

739

740

741

742

743

744

745

746

747

748

749

750

751

752

753

754

755

756

757

758

759

760

761

and investigating loci filtering. Sci Rep 7:1-14. https://doi.org/10.1038/s41598-017-168107

Huang H, Lacey Knowles L (2016) Unforeseen consequences of excluding missing data from next-generation sequences: Simulation study of rad sequences. Syst Biol 65:357-365. https://doi.org/10.1093/sysbio/syu046

Huson DH, Bryant D (2006) Application of phylogenetic networks in evolutionary studies. Mol Biol Evol 23:254-267. https://doi.org/10.1093/molbev/msj030

Joly S, McLenachan PA, Lockhart PJ (2009) A statistical approach for distinguishing hybridization and incomplete lineage sorting. Am Nat 174:. https://doi.org/10.1086/600082

Jombart T, Ahmed I (2011) adegenet 1.3-1: New tools for the analysis of genome-wide SNP data. Bioinformatics 27:3070-3071. https://doi.org/10.1093/bioinformatics/btr521

Kalyaanamoorthy S, Minh BQ, Wong TKF, et al (2017) ModelFinder: Fast model selection for accurate phylogenetic estimates. Nat Methods 14:587-589. https://doi.org/10.1038/nmeth.4285

Katoh K, Standley DM (2013) MAFFT multiple sequence alignment software version 7: Improvements in performance and usability. Mol Biol Evol 30:772-780. https://doi.org/10.1093/molbev/mst010

Kieneke A, Martínez Arbizu PM, Fontaneto D (2012) Spatially structured populations with a low level of cryptic diversity in European marine Gastrotricha. Mol Ecol 21:1239-54. https://doi.org/10.1111/j.1365-294X.2011.05421.x

Knowlton N (1993) Sibling species in the sea. Annu Rev Ecol Syst 24:189-216

Korshunova T, Martynov A, Bakken T, Picton B (2017) External diversity is restrained by internal conservatism: New nudibranch mollusc contributes to the cryptic species problem. Zool Scr 46:683-692. https://doi.org/10.1111/zsc.12253

Kubatko LS, Degnan JH (2007) Inconsistency of phylogenetic estimates from concatenated data under coalescence. Syst Biol 56:17-24. https://doi.org/10.1080/10635150601146041 
762 Kück P, Longo GC (2014) FASconCAT-G: Extensive functions for multiple sequence alignment 763 preparations concerning phylogenetic studies. Front Zool 11:1-8.

764 https://doi.org/10.1186/s12983-014-0081-X

765 Kück P, Meusemann K (2010) FASconCAT: Convenient handling of data matrices. Mol

766

Phylogenet Evol 56:1115-1118. https://doi.org/10.1016/j.ympev.2010.04.024

767

768

769

770

771

772

773

774

775

776

777

778

779

780

781

782

783

784

785

786

787

788

Kück P, Struck TH (2014) BaCoCa - A heuristic software tool for the parallel assessment of sequence biases in hundreds of gene and taxon partitions. Mol Phylogenet Evol 70:94-98. https://doi.org/10.1016/j.ympev.2013.09.011

Lavoué S, Miya M, Arnegard ME, et al (2011) Remarkable morphological stasis in an extant vertebrate despite tens of millions of years of divergence. Proc Biol Sci / R Soc 278:10031008. https://doi.org/10.1098/rspb.2010.1639

Leaché AD, Zhu T, Rannala B, Yang Z (2019) The Spectre of Too Many Species. Syst Biol 68:168-181. https://doi.org/10.1093/sysbio/syy051

Leasi F, Norenburg JL (2014) The necessity of DNA taxonomy to reveal cryptic diversity and spatial distribution of meiofauna, with a focus on Nemertea. PLoS One 9:. https://doi.org/10.1371/journal.pone.0104385

Lee CE, Frost BW (2002) Morphological stasis in the Eurytemora affinis species complex (Copepoda: Temoridae). In: Hydrobiologia. pp 111-128

Lee KM, Kivela SM, Ivanov V, et al (2018) Information Dropout Patterns in Restriction Site Associated DNA Phylogenomics and a Comparison with Multilocus Sanger Data in a Species-Rich Moth Genus. Syst Biol 1-15. https://doi.org/10.1093/sysbio/syy029

Li G, Figueiró H V., Eizirik E, et al (2019) Recombination-Aware Phylogenomics Reveals the Structured Genomic Landscape of Hybridizing Cat Species. Mol Biol Evol 36:2111-2126. https://doi.org/10.1093/molbev/msz139

Malinsky M, Svardal H, Tyers AM, et al (2018) Whole-genome sequences of Malawi cichlids reveal multiple radiations interconnected by gene flow. Nat Ecol Evol 2:1940-1955. https://doi.org/10.1038/s41559-018-0717-x 
789 Melo-Ferreira J, Boursot P, Carneiro M, et al (2012) Recurrent introgression of mitochondrial 790 DNA among hares (lepus spp.) revealed by species-tree inference and coalescent 791 simulations. Syst Biol 61:367-381. https://doi.org/10.1093/sysbio/syr114

792 Nadler SA, De Len GPP (2011) Integrating molecular and morphological approaches for 793 characterizing parasite cryptic species: Implications for parasitology. Parasitology 794 138:1688-1709. https://doi.org/10.1017/S003118201000168X

795

796

797

798

799

800

801

802

803

804

805

806

807

808

809

810

811

812

813

814

815

Nguyen LT, Schmidt HA, Von Haeseler A, Minh BQ (2015) IQ-TREE: A fast and effective stochastic algorithm for estimating maximum-likelihood phylogenies. Mol Biol Evol 32:268-274. https://doi.org/10.1093/molbev/msu300

Novo M, Almodóvar A, Fernández R, et al (2010) Cryptic speciation of hormogastrid earthworms revealed by mitochondrial and nuclear data. Mol Phylogenet Evol 56:507-512. https://doi.org/10.1016/j.ympev.2010.04.010

Novo M, Almodóvar A, Fernández R, et al (2012) Appearances can be deceptive: Different diversification patterns within a group of mediterranean earthworms (Oligochaeta, Hormogastridae). Mol Ecol 21:3776-3793. https://doi.org/10.1111/j.1365294X.2012.05648.x

O'Leary SJ, Puritz JB, Willis SC, et al (2018) These aren't the loci you'e looking for: Principles of effective SNP filtering for molecular ecologists. Mol Ecol 27:3193-3206. https://doi.org/10.1111/mec.14792

Palumbi S, Martin A, Romano S, et al (1991) The simple fool's guide to PCR, version 2.

Pante E, Puillandre N, Viricel A, et al (2015) Species are hypotheses: avoid connectivity assessments based on pillars of sand. Mol Ecol 24:525-544. https://doi.org/10.1111/mec.13048

Paradis E, Schliep K (2018) Ape 5.0: An environment for modern phylogenetics and evolutionary analyses in R. Bioinformatics 35:526-528. https://doi.org/10.1093/bioinformatics/bty633

Paris JR, Stevens JR, Catchen JM (2017) Lost in parameter space: a road map for stacks. 
817 Patterson N, Moorjani P, Luo Y, et al (2012) Ancient admixture in human history. Genetics 192:1065-1093. https://doi.org/10.1534/genetics.112.145037

819

820

821

822

823

824

825

826

827

828

829

830

831

832

833

834

835

836

837

838

839

840

841

Pease JB, Haak DC, Hahn MW, Moyle LC (2016) Phylogenomics Reveals Three Sources of Adaptive Variation during a Rapid Radiation. PLoS Biol 14:1-24. https://doi.org/10.1371/journal.pbio.1002379

Pérez-Ponce de León G, Poulin R (2016) Taxonomic distribution of cryptic diversity among metazoans: not so homogeneous after all. Biol Lett 12:20160371. https://doi.org/10.1098/rsb1.2016.0371

Peter BM (2016) Admixture, population structure, and f-statistics. Genetics 202:1485-1501. https://doi.org/10.1534/genetics.115.183913

Peterson BK, Weber JN, Kay EH, et al (2012) Double digest RADseq: An inexpensive method for de novo SNP discovery and genotyping in model and non-model species. PLoS One 7:. https://doi.org/10.1371/journal.pone.0037135

Pfenninger M, Schwenk K (2007) Cryptic animal species are homogeneously distributed among taxa and biogeographical regions. BMC Evol Biol 7:121. https://doi.org/10.1186/14712148-7-121

Rice P, Longden L, Bleasby A (2000) EMBOSS: The European Molecular Biology Open Software Suite. Trends Genet 16:276-277. https://doi.org/10.1016/S0168-9525(00)02024-2

Rochette N, Rivera-Colón A, Catchen JM (2019) Stacks2: Analytical methods for paired-end sequencing improve RADseq-based population genomics. Mol Ecol. https://doi.org/10.1111/mec.15253

Rochette NC, Catchen JM (2017) Deriving genotypes from RAD-seq short-read data using Stacks. Nat Protoc 12:2640-2659. https://doi.org/10.1038/nprot.2017.123

Rozas J, Ferrer-Mata A, Sánchez-DelBarrio JC, et al (2017) DnaSP 6: DNA sequence polymorphism analysis of large data sets. Mol Biol Evol 34:3299-3302. 
842

843 844 845

846

847

848

849

850

851

852

853

854

855

856

857

858

859

860

861

862

863

864

865

866

867

https://doi.org/10.1093/molbev/msx248

Santamaria CA, Mateos M, Dewitt TJ, Hurtado LA (2016) Constrained body shape among highly genetically divergent allopatric lineages of the supralittoral isopod Ligia occidentalis (Oniscidea). Ecol Evol 6:1537-1554. https://doi.org/10.1002/ece3.1984

Scornavacca C, Galtier N (2017) Incomplete lineage sorting in mammalian phylogenomics. Syst Biol 66:112-120. https://doi.org/10.1093/sysbio/syw082

Sloan DB, Havird JC, Sharbrough J (2017) The on-again, off-again relationship between mitochondrial genomes and species boundaries. Mol Ecol 26:2212-2236. https://doi.org/10.1111/mec.13959

Smith MA, Eveleigh ES, McCann KS, et al (2011) Barcoding a quantified food web: Crypsis, concepts, ecology and hypotheses. PLoS One 6:. https://doi.org/10.1371/journal.pone.0014424

Song S, Liu L, Edwards S V, Wu S (2015) Erratum: Resolving conflict in eutherian mammal phylogeny using phylogenomics and the multispecies coalescent model (Proceedings of the National Academy of Sciences of the United States of America (2012) 109 (14942-14947) (DOI:10.1073/pnas.1211733109)). Proc Natl Acad Sci U S A 112:E6079. https://doi.org/10.1073/pnas.1518753112

Struck TH, Cerca J (2019) Cryptic species and their Evolutionary significance. eLS 1-9. https://doi.org/10.1002/9780470015902.a0028292

Struck TH, Feder JL, Bendiksby M, et al (2018) Finding evolutionary processes hidden in cryptic species. Trends Ecol Evol 1-11. https://doi.org/10.1016/j.tree.2017.11.007

Suh A, Smeds L, Ellegren H (2015) The dynamics of incomplete lineage sorting across the ancient adaptive radiation of neoavian birds. PLoS Biol 13:1-18. https://doi.org/10.1371/journal.pbio.1002224

Suvorov A, Kim BY, Wang J, et al (2020) Widespread introgression across a phylogeny of 155 Drosophila genomes. bioRxiv 2020.12.14.422758 
868 Swift HF, Daglio LG, Dawson MN (2016) Three routes to crypsis: stasis, convergence, and 869 parallelism in the Mastigias species complex (Scyphozoa, Rhizostomeae). Mol Phylogenet $870 \quad$ Evol 99:103-115. https://doi.org/10.1016/j.ympev.2016.02.013

871 Taylor SA, Larson EL (2019) Insights from genomes into the evolutionary importance and 872 prevalence of hybridization in nature. Nat Ecol Evol 3:170-177.

873 https://doi.org/10.1038/s41559-018-0777-y

874 Valtueña FJ, López J, Álvarez J, et al (2016) Scrophularia arguta, a widespread annual plant in 875 the Canary Islands: a single recent colonization event or a more complex phylogeographic 876 pattern? Ecol Evol 6:4258-4273. https://doi.org/10.1002/ece3.2109

877 Wada S, Kameda Y, Chiba S (2013) Long-term stasis and short-term divergence in the 878 phenotypes of microsnails on oceanic islands. Mol Ecol 22:4801-10.

879 https://doi.org/10.1111/mec.12427

880

881

882

883

884

885

886

887

888

889

890

891

892

893

894

Wares JP, Cunningham CW (2001) Phylogeography and historical ecology of the North Atlantic intertidal. Evolution 55:2455-2469. https://doi.org/10.1111/j.0014-3820.2001.tb00760.x

Weber AA-T, Stöhr S, Chenuil A (2019) Species delimitation in the presence of strong incomplete lineage sorting and hybridization. Mol Phylogenet Evol 131:240218. https://doi.org/10.1101/240218

Weir BS, Cockerham CC (1984) Estimating F-statistics for the analysis of population structure. Evolution (N Y) 38:1358-1370. https://doi.org/10.2307/2408641

Westheide W, Purschke G (1988) Organism processing. In: Higgins RP, Thiel H (eds) Introduction to the study of meiofauna. Smithsonian Institution Press, Washington, pp 146160

Zanol J, Halanych KM, Struck TH, Fauchald K (2010) Phylogeny of the bristle worm family Eunicidae (Eunicida, Annelida) and the phylogenetic utility of noncongruent 16S, COI and 18S in combined analyses. Mol Phylogenet Evol 55:660-676. https://doi.org/10.1016/j.ympev.2009.12.024

Zuccarello GC, West JA, Kamiya M (2018) Non-monophyly of Bostrychia simpliciuscula 
895 (Ceramiales, Rhodophyta): Multiple species with very similar morphologies, a revised

896 taxonomy of cryptic species. Phycol Res 66:100-107. https://doi.org/10.1111/pre.12207

897

898

899 


\section{Figure 1}

Figure 1. Sampling locations across the Northern Atlantic.

A-B) North America, C) United Kingdom, France and Germany, and the Island of Sylt in Germany. The three species are displayed in different colours: orange (Stygocapitella westheidei), green (S. josemariobrancoi) and blue (S. subterranea). Sampling locations with multiple circles denote populations in sympatry. Species are delimited using the COI, 16S, 18 S and ITS1 barcodes. 

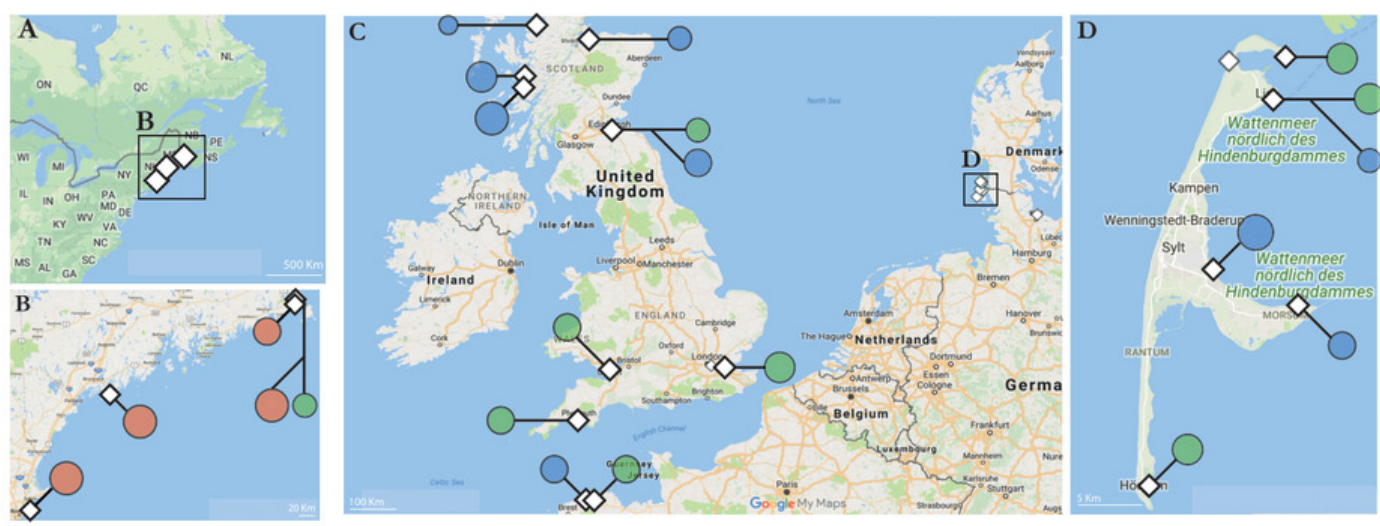

Sampling size

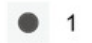

() 2

3

4

5

Species

S. subterranea

S. josemariobrancoi

S. westheidei 


\section{Figure 2}

Figure 2. Phylogenetic reconstruction and Scanning Electron Microscopy images of Stygocapitella.

A) Maximum likelihood phylogeny of a concatenated, partitioned dataset (COI, 16S, $18 \mathrm{~S}$ and ITS1), with scale provided on the bottom. Coloration follows species, with blue representing Stygocapitella subterranea, green representing S. josemariobrancoi, and orange $S$. westheidei. Bootstrap support for the branches representing species are provided on top of the branches. Every species is retrieved as monophyletic. B) Drawing of the Stygocapitella westheidei, S. subterranea, S. josemariobrancoi morphotype. For more information on the classification and distinction of the morphotypes see Cerca et. al (2020). C) Phylogenomic tree based on 4,737 RADseq loci. Bootstrap support is provided for the main branches. Coloration follows species with blue representing Stygocapitella subterranea, green representing S. josemariobrancoi, and orange $S$. westheidei. Three specimens, denoted by arrows, are identified as 'paraphyletic', including Bristol Channel 42204 (identified as S. josemariobrancoi, nested within S. subterranea), Bristol Channel 42205 (identified as S. josemariobrancoi, nested within S. westheidei) and St. Efflam 40103 (identified as S. josemariobrancoi, nested sister to $S$. subterranea). The tree topology is coloured with shared pairwise data as estimated by BaCoCa. Allele 0 and allele 1 are displayed for all specimens. Specimen $222 \_01$ is a technical replicate and is therefore represented twice. Shared pairwise data was calculated by integrating BaCoCa's information on pairwise missing data. 


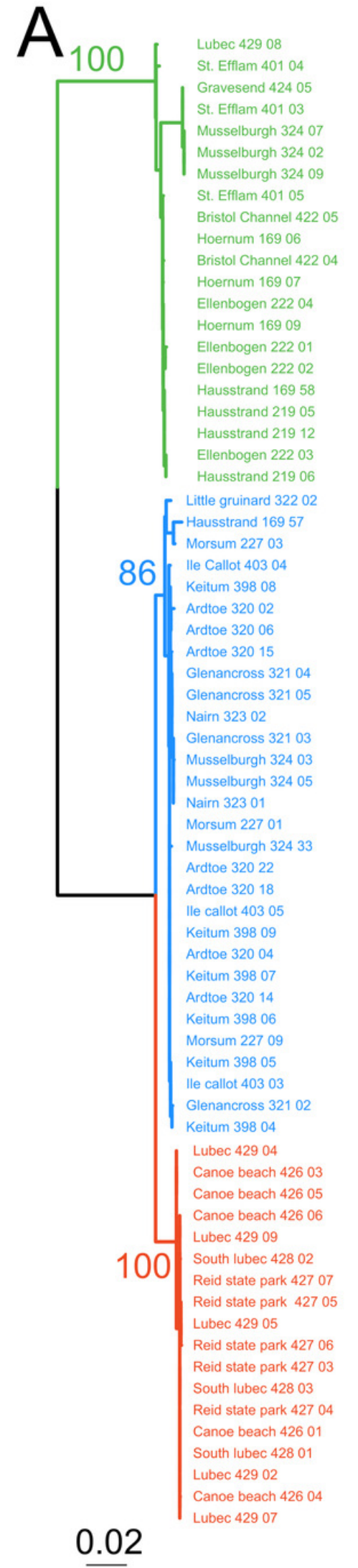

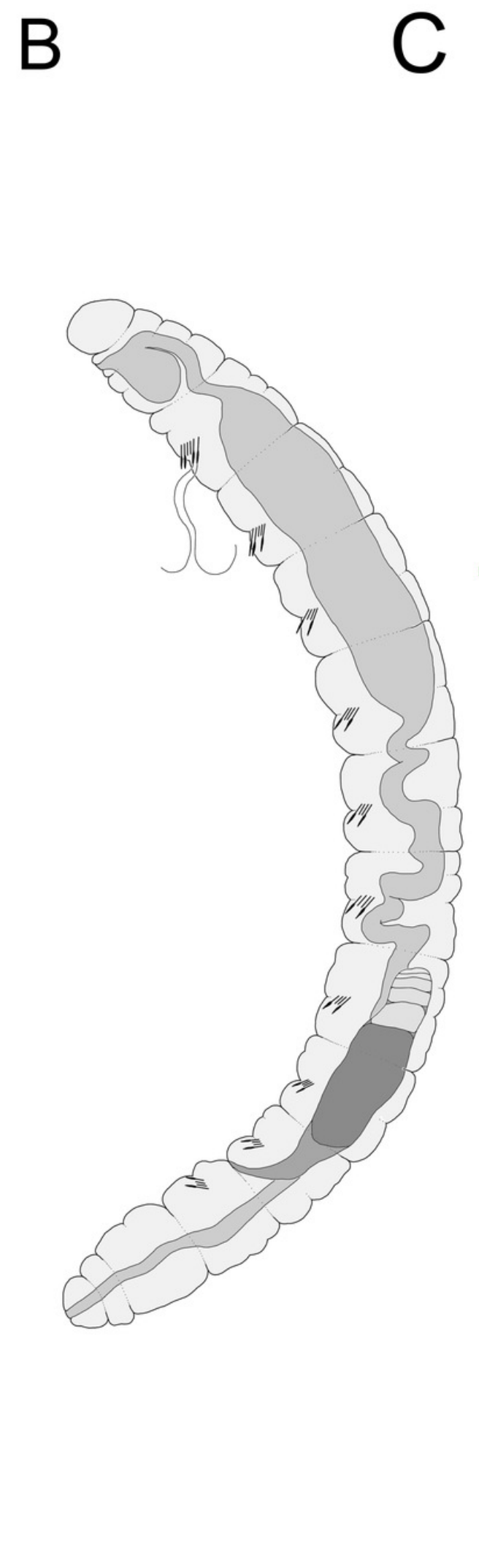

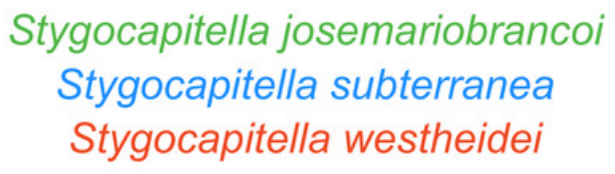

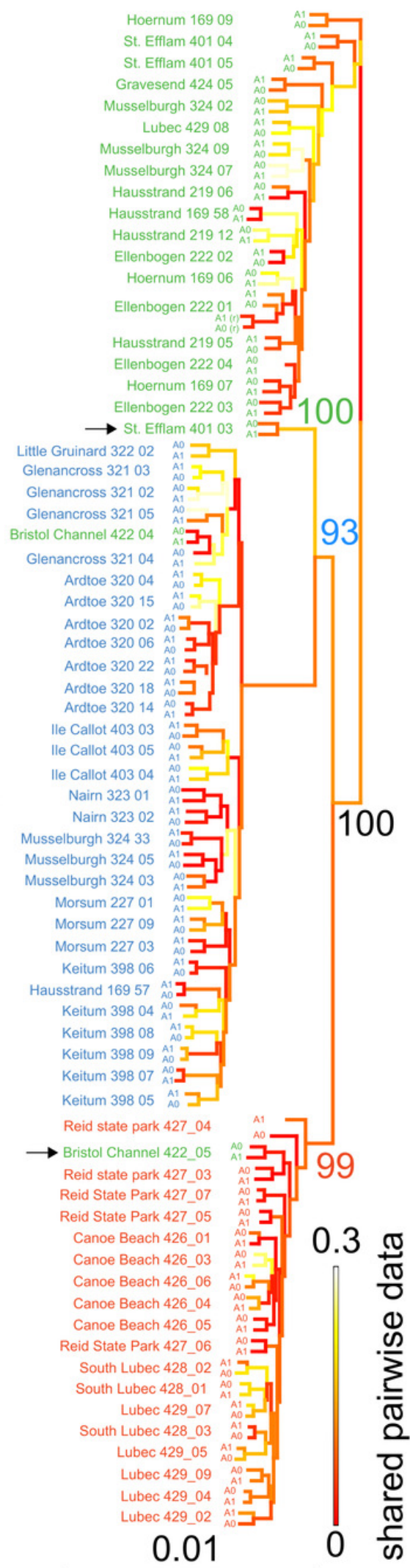
Bristol Channel 42204

Ardtoe 32014 A

- Callot 40305

e Callot 40304

Musselburgh 32433

sselburgh 32403

Keitum 39804

Keitum 39809 A ${ }_{\mathrm{A} A}^{\mathrm{A}} \mathrm{I}$

Keitum 39805 A0 3

Bristol Channel 422 o5

Reid state park 427

Reid State Park 427 O7

Canoe Beach 426 03

Canoe Beach 426 05

Sate Park 427_06

South Lubec 428_01 bec 429 -

ubec 429_05 A0 ב-

ec 429_09 A1 구

Lubec 429_02 ÂA

0.01

0 क 


\section{Figure 3}

Phylogenetic network based on 4,737 RADseq loci.

Coloration follows species with blue representing Stygocapitella subterranea, green representing S. josemariobrancoi, and orange representing S. westheidei. Specimens with arrows represent specimens which were as paraphyletic in the phylogenomic tree (Fig. $2 \mathrm{C}$ ). S. josemariobrancoi is clearly stretched, indicating a greater differentiation from the remaining two species. In congruence with the phylogenomic analysis, Bristol Channel 422 04 is nested within S. subterranea. 


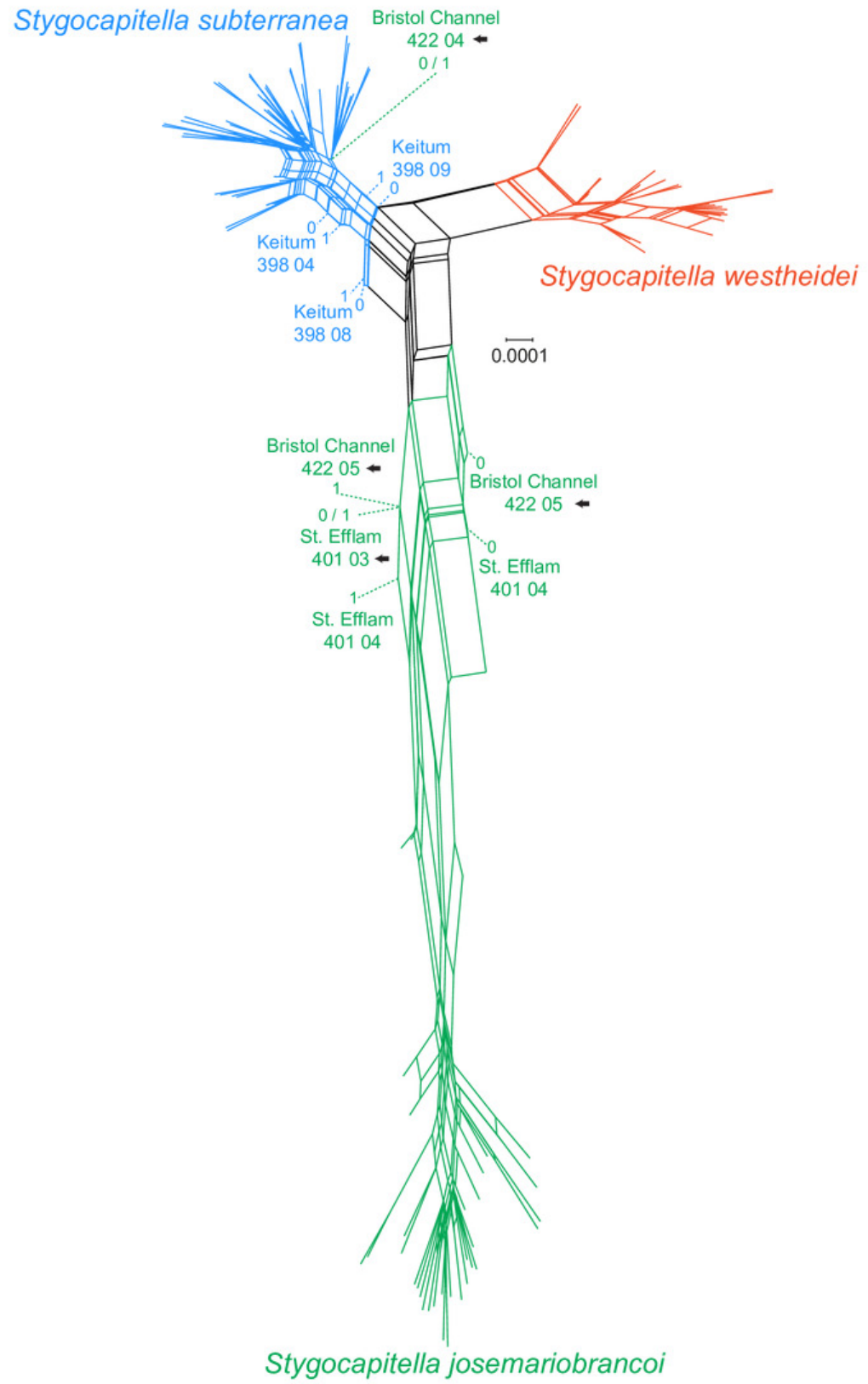




\section{Figure 4}

Principal Component Analysis (A) and Multi-dimensional scaling (B) of 3,428 SNPs.

The percentage of explained variation is displayed with the axis for the PCA. Lineage (species) are given in different shapes, with colours represent populations. Specimens with 'intermediate positions' are highlighted both analyses, indicating potential shared generated variation between specimens. 

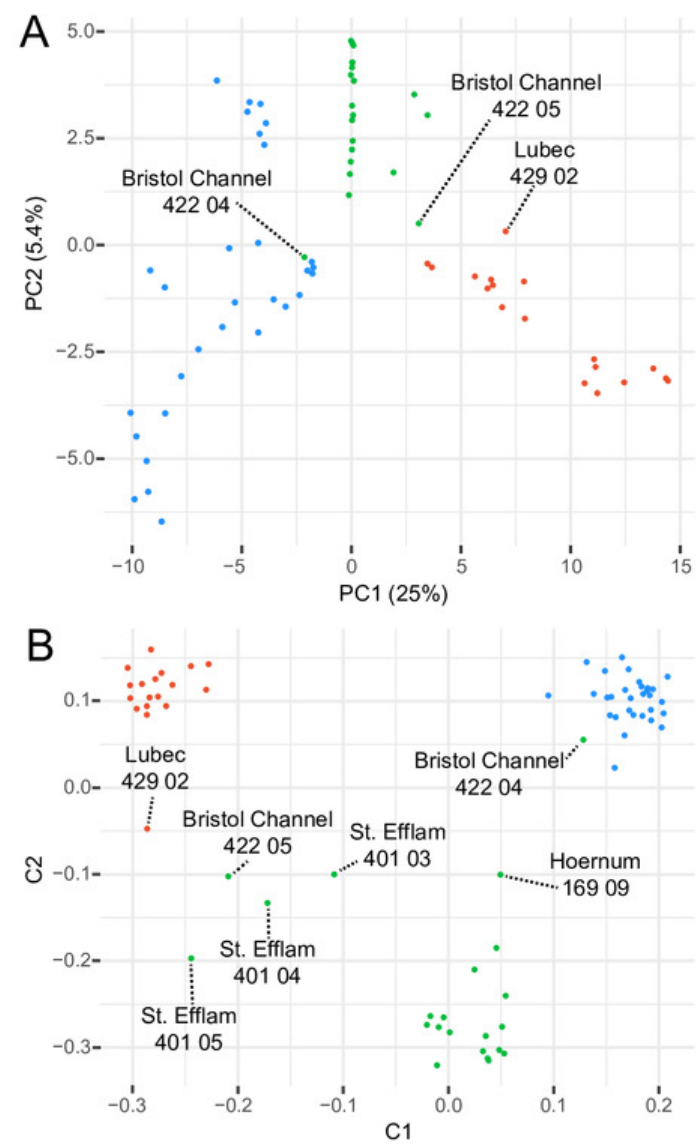

- Stygocapitella subterranea

- Stygocapitella josemariobrancoi

- Stygocapitella westheidei 


\section{Figure 5}

ADMIXTURE analysis of 3,428 SNPs shows shared genetic variation.

Stygocapitella josemariobrancoi, S. subterranea and S. westheidei are plotted consecutively from left to right. Populations and specimen-ids are denoted at the bottom, with sympatricpopulations in bold and italics. The cladogram follows the tree topology retrieved in Figure 2 A and 2 B. 


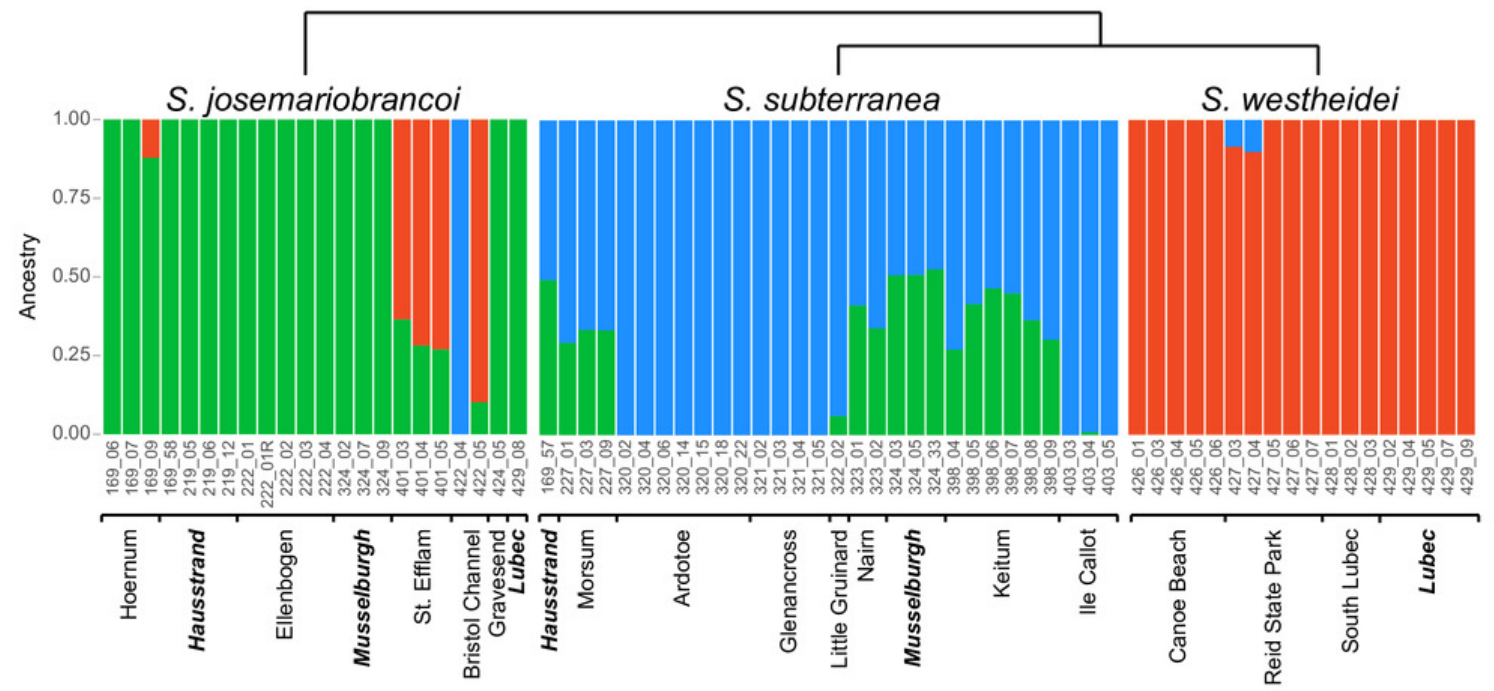




\section{Figure 6}

Figure 6. Demographic scenarios considered.

The likelihood of different demographic scenarios is displayed on the $Y$ axis. Based on the estimated phylogeny (Figure 2), we modelled scenarios for (from left to right): 1) geographic gene flow (gene flowbetween $S$. josemariobrancoi and the ancient lineage, and $S$. josemariobrancoi and S. subterranea); 2) ancient gene flow (gene flow between $S$. josemariobrancoi and the lineage before the $S$. subterranea and $S$. westheidei split); 3) no gene flow at all; 4) ancient gene flow and gene flow between $S$. subterranea and $S$. westheidei; 5) gene flow only between $S$. westheidei and S. subterranea; 6) gene flow in every possible branch; 7) gene flow in sympatric, European linages; 8) gene flow between $S$. josemariobrancoi and S. westheidei; 9) gene flow between currently existing lineages; 10) ancient gene flow with gene flow between S. josemariobrancoi and S. westheidei. 


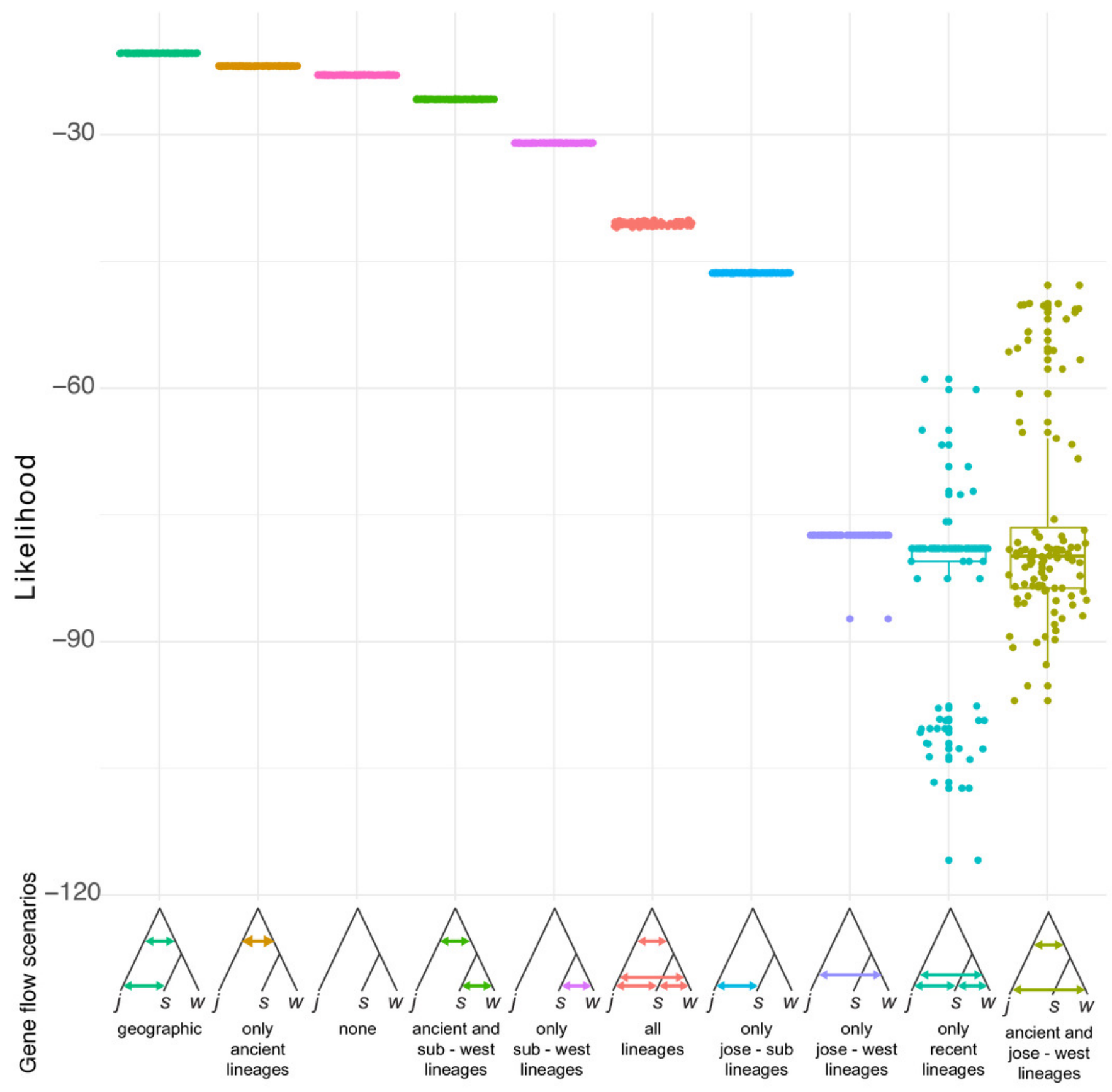




\section{Table $\mathbf{1}$ (on next page)}

f3 statistics testing for hybridization between lineages.

Each row represents a scenario where two species are the source for admixture, and the third species is the target of hybridization. A f3 statistic, the standard error (SE) and a Zscore value calculated with jackknife is provided for each scenario based. 
1 Table $1 \mathrm{f3}$ statistics testing for hybridization between lineages. Each row represents a scenario where 2 two species are the source for admixture, and the third species is the target of hybridization. A $f 3$ statistic, 3 the standard error (SE) and a Z-score value calculated with jackknife is provided for each scenario based.

\begin{tabular}{cccccc}
\hline Source 1 & Source 2 & Target & f3 & SE & Z \\
\hline S. subterranea & S. josemariobrancoi & S. westheidei & 0.91 & 0.08 & 11.424 \\
S. josemariobrancoi & S. westheidei & S. subterranea & 1.09 & 0.24 & 4.575 \\
S. westheidei & S. subterranea & S. josemariobrancoi & 0.25 & 0.10 & 2.605
\end{tabular}

4 


\section{Table 2 (on next page)}

Weir-Cockherham Fst-estimate

Estimates are provided in the lower part of the table, and the number of individuals included in the pairwise estimation is provided in the upper part of the table. 
1 Table 2 Weir-Cockherham Fst-estimate is provided in the lower part of the table, and the number of 2 individuals included in the pairwise estimation is provided in the upper part of the table.

\begin{tabular}{cccc}
\hline Species & S. subterranea & S. josemariobrancoi & S. westheidei \\
\hline S. subterranea & - & 52 & 48 \\
S. josemariobrancoi & 0.530 & - & 40 \\
S. westheidei & 0.664 & 0.492 & -
\end{tabular}

3 


\section{Table 3 (on next page)}

Summary statistics for the various analysed populations

For each site we provide the number of specimens and chromossomes, number of loci considered, S (Waterson's estimate), the averaged $\pi$, and the averaged Tajima's D. Analysed populations include those with $>5$ chromossomes, with the exception of Plymouth which had no samples with no missing data. 
1 Table 3 Summary statistics for the various analysed populations. For each site we provide the number of 2 specimens and chromossomes, number of loci considered, S (Waterson's estimate), the averaged $\pi$, and 3 the averaged Tajima's D. Analysed populations include those with $>5$ chromossomes, with the exception 4 of Plymouth which had no samples with no missing data.

\begin{tabular}{|c|c|c|c|c|c|c|}
\hline Species & Site & $\begin{array}{c}\text { Number of specimens } \\
\text { (chromossomes) }\end{array}$ & $\begin{array}{c}\text { Number of loci } \\
\text { analyzed (without } \\
\text { missing data) }\end{array}$ & $\begin{array}{c}\mathbf{S} \\
\text { (Waterson's } \\
\text { estimate) }\end{array}$ & $\begin{array}{c}\text { Averaged } \\
\pi\end{array}$ & $\begin{array}{c}\text { Averaged } \\
\text { Tajima's D }\end{array}$ \\
\hline \multirow{9}{*}{$\begin{array}{c}\text { Stygocapitella } \\
\text { subterranea }\end{array}$} & Ardtoe & $7(14)$ & 122 & 2.1066 & 0.0020 & -0.1843 \\
\hline & Glenancross & $4(8)$ & 658 & 2.1763 & 0.0029 & 0.1123 \\
\hline & Hausstrand & 1 (not analyzed) & - & & - & \\
\hline & Ile Callot & $3(6)$ & 1301 & 2.3912 & 0.0037 & 0.1958 \\
\hline & Keitum & $6(12)$ & 40 & 2.525 & 0.0030 & -0.1858 \\
\hline & $\begin{array}{c}\text { Little } \\
\text { Gruinard }\end{array}$ & 1 (not analyzed) & - & - & - & - \\
\hline & Morsum & $3(6)$ & 1923 & 2.1482 & 0.0032 & 0.1326 \\
\hline & Musselburgh & $3(6)$ & 1166 & 2.1329 & 0.0033 & 0.1571 \\
\hline & Nairn & 2 (not analyzed) & - & - & - & - \\
\hline \multirow[t]{9}{*}{$\begin{array}{c}\text { Stygocapitella } \\
\text { josemariobrancoi }\end{array}$} & $\begin{array}{c}\text { Bristol } \\
\text { Channel }\end{array}$ & 2 (not analyzed) & - & - & - & - \\
\hline & Ellenbogen & $4(8)$ & 403 & 1.6377 & 0.0024 & -0.1993 \\
\hline & Gravesend & 2 (not analyzed) & - & - & - & - \\
\hline & Hausstrand & $4(8)$ & 154 & 2.5519 & 0.0038 & -0.3862 \\
\hline & Hoernum & $3(6)$ & 261 & 2.6858 & 0.0046 & -0.0281 \\
\hline & Lubec & 1 (not analyzed) & - & - & - & - \\
\hline & Plymouth & 0 (not analyzed) & - & - & - & - \\
\hline & Musselburgh & $3(6)$ & 414 & 2.5918 & 0.0045 & -0.0356 \\
\hline & Saint Efflam & $3(6)$ & 572 & 3.3969 & 0.0059 & 0.1702 \\
\hline \multirow{4}{*}{$\begin{array}{l}\text { Stygocapitella } \\
\text { westheidei }\end{array}$} & Canoe Beach & $5(10)$ & 577 & 1.8128 & 0.0021 & -0.3654 \\
\hline & Lubec & $5(10)$ & 89 & 2.1461 & 0.0029 & -0.1044 \\
\hline & $\begin{array}{l}\text { Reid State } \\
\text { Park }\end{array}$ & $5(10)$ & 519 & 2.3468 & 0.0024 & -0.5266 \\
\hline & South Lubec & $3(6)$ & 524 & 2.0115 & 0.0034 & 0.1723 \\
\hline
\end{tabular}

